\title{
Erectile Dysfunction in Men on the Rise: Is There a Link with Endocrine Disrupting Chemicals?
}

\author{
Samuel M. Cripps Deidre M. Mattiske Andrew J. Pask \\ School of BioSciences, The University of Melbourne, Melbourne, VIC, Australia
}

\section{Keywords}

Differences of sexual development · Early mammalian development · Endocrine-disrupting chemicals · Erectile dysfunction - Erection

\begin{abstract}
Erectile dysfunction (ED) is one of the most prevalent chronic conditions affecting men. ED can arise from disruptions during development, affecting the patterning of erectile tissues in the penis and/or disruptions in adulthood that impact sexual stimuli, neural pathways, molecular changes, and endocrine signalling that are required to drive erection. Sexual stimulation activates the parasympathetic system which causes nerve terminals in the penis to release nitric oxide (NO). As a result, the penile blood vessels dilate, allowing the penis to engorge with blood. This expansion subsequently compresses the veins surrounding the erectile tissue, restricting venous outflow. As a result, the blood pressure localised in the penis increases dramatically to produce a rigid erection, a process known as tumescence. The sympathetic pathway releases noradrenaline (NA) which causes detumescence: the reversion of the penis to the flaccid state. Androgen signalling is critical for erectile function through its role in penis development and in regulating the physiological processes driving erection in the adult. Interestingly, estrogen signalling is also implicated in penis development
\end{abstract}

karger@karger.com

(c) 2021 S. Karger AG, Basel

www.karger.com/sxd

Karger" and potentially in processes which regulate erectile function during adulthood. Given that endocrine signalling has a prominent role in erectile function, it is likely that exposure to endocrine disrupting chemicals (EDCs) is a risk factor for $E D$, although this is an under-researched field. Thus, our review provides a detailed description of the underlying biology of erectile function with a focus on the role of endocrine signalling, exploring the potential link between EDCs and ED based on animal and human studies.

(c) 2021 S. Karger AG, Basel

\section{Erectile Dysfunction}

Erectile Dysfunction (ED) is defined as the consistent or repeated inability to acquire or sustain an erection sufficient for satisfactory sexual performance [McCabe et al., 2016]. The 5-item International Index of Erectile Function (IIEF-5) self-questionnaire categorises the severity of ED based on the numerical score (each of the 5 questions is worth 5 points) as no $\mathrm{ED}(22-25)$, mild (17-21), mild to moderate (12-16), moderate $(8-11)$, or severe $(1-7)$ [Rhoden et al., 2002]. Erectile function relies on a combination of organic (structural, neurologic, vascular, and endocrine) and psychogenic factors. Thus, ED can have a number of aetiologies which are broadly classified as either organic or psychogenic [Johannes et al., 2000]. Psy- 
chogenic risk factors for ED include depression and anxiety [Yang et al., 2019], although these are beyond the scope of this review. Organic risk factors include vascular, neurologic, and endocrine abnormalities [reviewed in Ludwig and Phillips, 2014]. Interestingly, since the penile vascular tissue that is responsible for erection is a component of the global vascular system, ED of vascular origin is often an indicator of systemic endothelial dysfunction [Virag et al., 1981]. Thus, ED not only disrupts quality of life but can also be a strong indicator of cardiovascular disease [Gandaglia et al., 2014].

$\mathrm{ED}$ is one of the most prevalent chronic conditions and negatively impacts the quality of life of men and their partners [Fisher et al., 2005]. The exact prevalence of ED is difficult to estimate, because this relies on subjective data-gathering and self-questionnaires. The International Index of Erectile Function (IIEF) and the Massachusetts Male Ageing Study (MMAS)-derived questionnaires are the most commonly used for investigating ED in population studies. However, researchers use a number of other questionnaires and methods which significantly limits comparability of study results [Kessler et al., 2019]. In addition, population studies have traditionally focused on ED prevalence in older men ( $>40$ years) while overlooking younger men [Feldman et al., 1994; Corona et al., 2010; Weber et al., 2013]. As a result, it is challenging to understand the true prevalence of ED in different age groups.

In addition, different geographical regions and age demographics yield varying results, creating further complications in understanding the epidemiology of ED. For example, ED was reported at an overall prevalence of 23.2 and $61 \%$ in Australian men from the ages of 35 and 45 years, respectively [Weber et al., 2013; Martin et al., 2014], and as high as $81.5 \%$ in Malaysian men over the age of 18 years [Nordin et al., 2019]. The landmark MMAS revealed a prevalence of mild to moderate ED in $52 \%$ of men aged 40-70 years [Feldman et al., 1994], whereas the European Male Ageing Study (EMAS) found an average ED prevalence of $30 \%$ in men at ages $40-79$ years [Corona et al., 2010]. Although there are regional differences, it was estimated that ED affected 152 million men worldwide in 1995 and was predicted to increase to 322 million men globally by 2025 (using the lowest United Nations population projections) [Ayta et al., 1999; McKinlay, 2000].

Several studies have unequivocally demonstrated that ED prevalence increases with age [Feldman et al., 1994; Chew et al., 2008; Corona et al., 2010; Weber et al., 2013; Martin et al., 2014; Nordin et al., 2019]. Thus, the pre- dicted increase in ED prevalence between 1995 and 2025 can be linked to an increasing ageing male population; the global proportion of men aged over 65 years in 1995 was $4.2 \%$ and will increase to $9.5 \%$ by 2025 [reviewed in Ayta et al., 1999]. However, the dramatic increase of ED prevalence is too rapid to be explained by ageing or genetic mutation alone. This is further supported by an exceptionally high prevalence of ED in younger men. For example, a study using the IIEF-5 showed that Swiss men aged 18-25 years displayed a prevalence of 30\% [Mialon et al., 2012]. Another IIEF-based study demonstrated that ED prevalence in a population in India ranged from 9.9 to $13 \%$ in $18-40$-years-old men [Sathyanarayana Rao et al., 2015]. Similarly, in Western Australia, ED prevalence among men in their 20s and 30s was reported as 15.7 and $8.7 \%$, respectively [Chew et al., 2008]. It was also found that 1 in 4 Caucasian European men seeking medical help for new-onset ED were below 40 years of age [Capogrosso et al., 2013]. These results are consistent with the increase of younger men ( $<40$ years) consulting for ED in a Florence clinic from 5 to $15 \%$ between 2010 and 2015 [Rastrelli and Maggi, 2017]. The consistently high prevalence of ED in young men globally means that it cannot be due to increased reporting alone; ED prevalence is increasing across all age groups, not just alongside an increasing ageing population.

Thus, it is likely that environmental and lifestyle factors are responsible for current global trends in ED prevalence. Indeed, several of these factors, which include smoking and diet, are implicated in the development of ED [McVary et al., 2001; Bacon et al., 2006; Esposito et al., 2006; Francis et al., 2007; Ramírez et al., 2016]. However, the role of endocrine-disrupting chemicals (EDCs) in the aetiology of ED is unclear. The WHO defines an EDC as "an exogenous substance or mixture that alters function(s) of the endocrine system and consequently causes adverse health effects in an intact organism, or its progeny, or (sub) populations" [Johansson and Svingen, 2020]. The term EDC in this review refers specifically to chemicals which are known to alter hormonal pathways and cause adverse health effects in humans. Although these adverse health effects are not yet described to include ED, we present a logical connection between their impact on hormonal pathways and the development and regulation of erectile tissues.

Endocrine signalling, particularly that of androgens, affects erectile function by driving penis development and also by regulating pathways in the adult involved in erection [Murakami, 1987; Foresta et al., 2004; Miyagawa et al., 2009]. Correct development of the erectile tissues in 
the penis including the nerves, smooth muscle, vasculature, and other structural features is essential for adult erectile function. Although the role of androgens in erectile function is established, the role of other hormones in this process is not well understood. However, endogenous estrogen signalling has a recently discovered role in penis development [Cripps et al., 2019; Govers et al., 2019] and may also regulate aspects of adult physiology driving erection, including penile blood flow (discussed below). Thus, endogenous estrogen signalling during development and adulthood may contribute to erectile function. This is further supported by the presence of aromatase and estrogen receptors (ERs) throughout the rat and human penis [Jesmin et al., 2002; Dietrich et al., 2004].

ED is correlated with circulating testosterone and estrogen levels in men; a significantly higher level of circulating estrogen and a higher estrogen-testosterone ratio is found in men with ED [Chen et al., 2020]. Also, ageing is associated with reduced circulating testosterone, potentially explaining ageing-induced ED [reviewed in Tsametis and Isidori, 2018]. This data suggests that alterations to hormonal balance, which could potentially occur via EDCs, is likely to increase the risk of ED. Furthermore, the rapid increase in ED prevalence has occurred alongside our increasing exposure to EDCs via multiple sources, including plastics, plasticizers, and phytoestrogens [reviewed in Diamanti-Kandarakis et al., 2009]. Due to the lack of research investigating a link between EDCs and ED, it is difficult to give an indication of how significant a risk factor EDCs are for this condition. Thus, it is crucial to understand the potential role of EDC exposure as a risk factor for ED. However, we first need a comprehensive understanding of the physiological and developmental mechanisms which govern erectile function, with a focus on the role of endocrine signalling in this process, before speculating on how EDCs may impact these processes to cause ED.

\section{Physiology of Erectile Function}

\section{Neural Stimulation}

Penile erection is an involuntary response elicited by a variety of stimuli and can arise via psychogenic and reflexogenic mechanisms. Psychogenic stimulus occurs at supraspinal centres via the senses, such as visual stimulation and smell, and imaginary factors, such as recall and sexual fantasies [de Groat, 2017]. These central stimuli send signals to the sacral parasympathetic or thoroco-

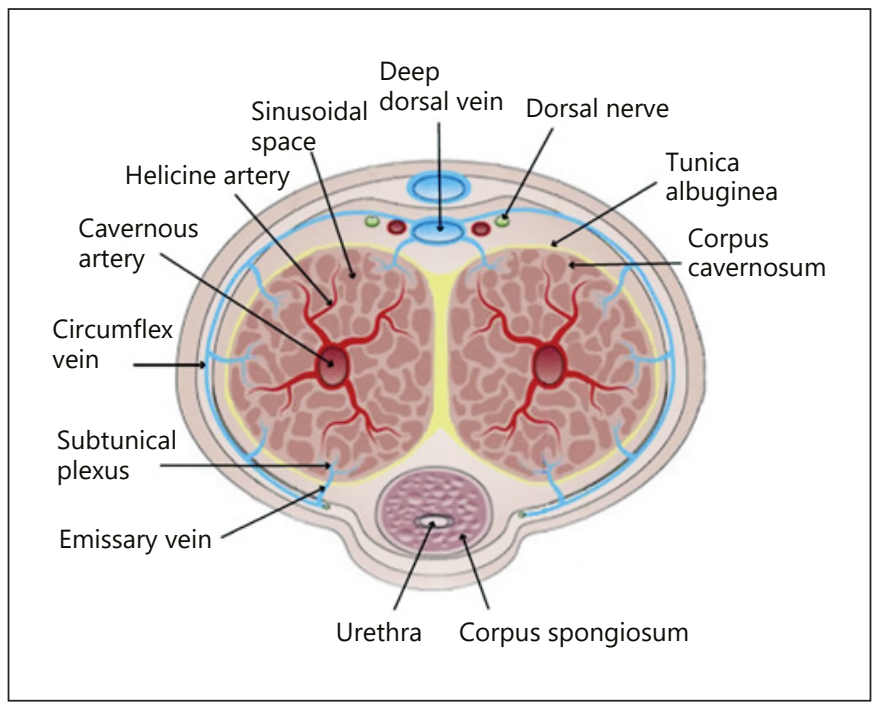

Fig. 1. Transverse section of an adult human penis [Yafi et al., 2016]. The corpus cavernosum (paired) and corpus spongiosum constitute the 3 erectile tissues of the penis. The tunica albuginea surrounds the corpora cavernosa. Blood flows into the corpus cavernosum via the cavernous artery, which branches into helicine arteries that supply the sinusoidal spaces. Blood drains from the sinusoidal spaces into the subtunical plexus, which forms the emissary vein that passes through the tunica albuginea. Emissary veins drain directly into the deep dorsal artery or into the circumflex veins which also drain into the deep dorsal artery. The dorsal nerve is a sensory somatic nerve fibre responsible for reflexogenic erections.

lumbar sympathetic spinal cord nuclei, which in turn transmit to the pelvic plexus [Reeves et al., 2016; de Groat, 2017]. These signals then travel through the cavernous nerve, a branch of the pelvic plexus, which innervates the erectile tissue of the penis [Colombel et al., 1999].

Reflexogenic stimulus involves stimulation of the dorsal nerve (Fig. 1), a sensory somatic nerve fibre in the penis, which relays messages to the spinal erection centres via the pudendal nerve [de Groat, 2017]. In turn, efferent nerves from the spine innervate the cavernous nerve as described for the psychogenic response above. Individuals with spinal cord injury above the sacral pathways maintain erectile responses, demonstrating the significance of the reflexogenic response in erectile function [Courtois et al., 1993]. Taken together, psychogenic and reflexogenic stimulation induce erection (tumescence) via stimulation of the cavernous nerve, which is composed of both parasympathetic and sympathetic nerve fibres [Yilmaz et al., 2006].

Parasympathetic stimulation of the cavernous nerve leads to increased blood flow within the penis, in turn 
Fig. 2. Androgen regulation of erectile tissue and molecular signalling involved in erectile physiology. Androgen signalling maintains non-adrenergic, non-cholinergic (NANC) nerve fibre and smooth muscle levels in the erectile tissue. Androgens also activate $\mathrm{K}^{+}$channels in smooth muscle, and androgen levels correlate with voltage-gated $\mathrm{Ca}^{2+}$ channel expression in the smooth muscle of the erectile tissue. Androgens positively regulate phosphodiesterase 5 (PDE5) in the smooth muscle and nitric oxide synthase (NOS) enzymes, which are localised NANC nerves and endothelial cells.

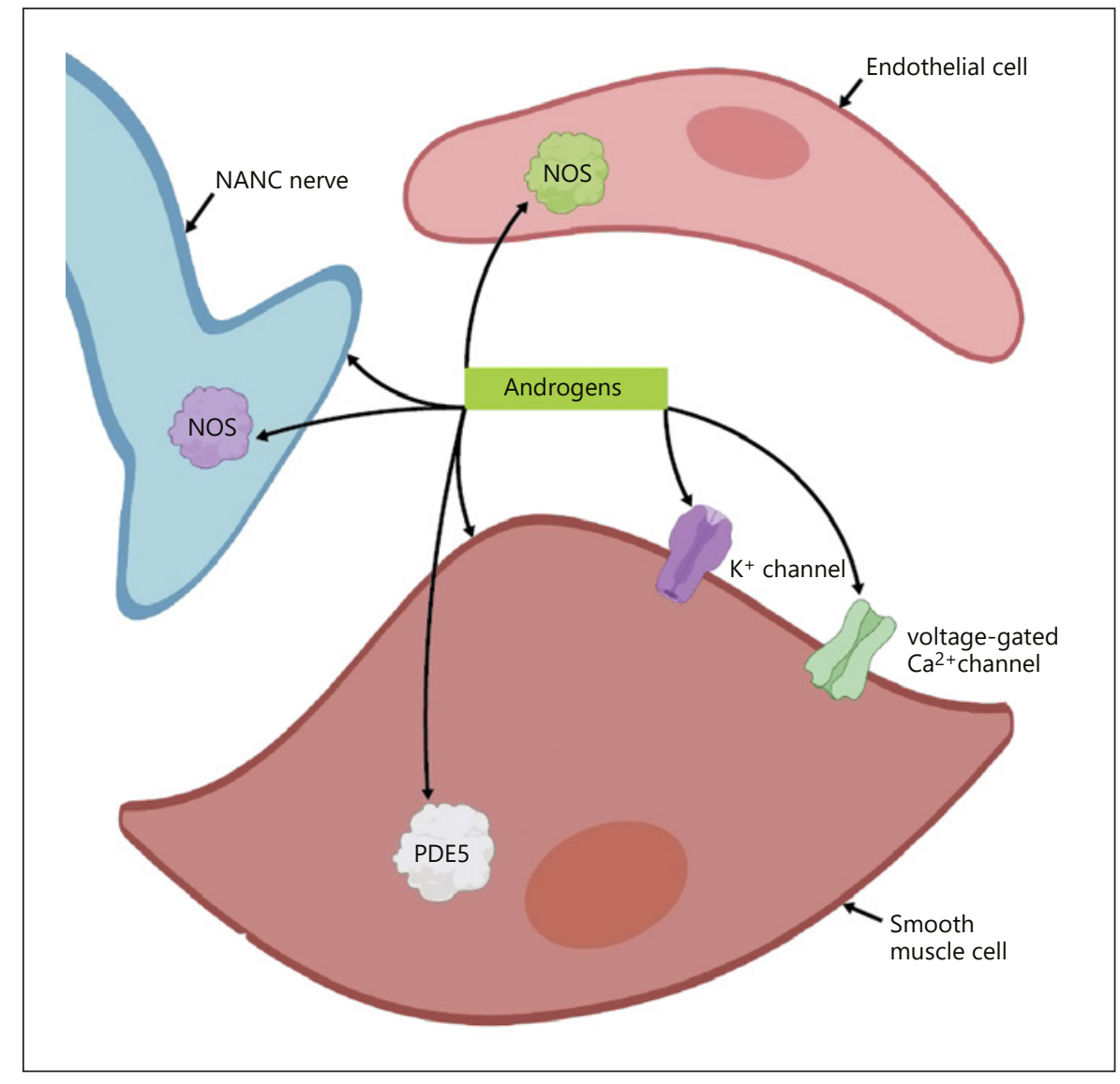

driving tumescence [Andersson and Wagner, 1995]. Stimulation of the sympathetic nerves reduces blood flow to the penis, leading to the flaccid state (detumescence) [Andersson and Wagner, 1995]. Somatic nerves also have a role in erectile function via contraction of the bulbocavernosus and ishiocavernosus muscles (described below).

Androgen signalling has been implicated in the regulation of nerve structure required for erectile function. For example, castration in rats leads to a reduction in the number of NOS-containing nerve fibres of the cavernosal and dorsal nerves [Baba et al., 2000]; the dorsal nerve is not purely a sensory somatic nerve but is also composed of autonomic NOS-containing nerve bundles [Burnett et al., 1993; Carrier et al., 1995]. This is consistent with the findings that rat castration leads to an altered structure of the dorsal nerve [Armagan et al., 2008] and a reduced density of NANC nerve fibres innervating the erectile tissue [Zvara et al., 1995; Schirar et al., 1997]. These studies show that androgen signalling maintains the neural circuitry within the penis which is critical for erectile activity (Fig. 2).
Estrogen is also a known neuroprotective agent, which is demonstrated by a variety of mechanisms in several animal and clinical studies [Brann et al., 2007]. For example, ERa protects rat neuronal cells in vitro via increasing $B c l$-XL mRNA (an anti-apoptotic transcript from $B c l-X$ ) and downregulating $B A D$ (considered a pro-apoptotic gene) [Gollapudi and Oblinger, 1999]. In addition, estrogen inhibits amyloid-beta-induced apoptosis and modulates apoptotic mechanisms such as maintaining expression of $B c l 2$ (an anti-apoptotic gene) in rat hippocampal cells in vitro [Nilsen et al., 2006]. Future studies need to elucidate whether estrogen also exerts neuroprotection within the erectile tissue, although the expression of ERs in the dorsal nerve of the rat glans penis suggests this may occur [Jesmin et al., 2002].

\section{Anatomy, Vasculature, and Hemodynamics of Erection}

The erectile tissue within the penis comprises 3 cylindrical structures: the paired corpus cavernosa which are dorsal to the urethra and the smaller corpus spongiosum 
which encloses the urethra and forms the glans distally [Kuno et al., 2001]. The penile artery supplies the penis with blood and branches into the dorsal, bulbourethral, and the cavernous arteries [Keegan and Penson, 2013]. The cavernous arteries lie within the corpus cavernosa and branch into the helicine arteries, which supply the sinusoidal spaces [Smith and Axilrod, 2007; Keegan and Penson, 2013]. Sinusoidal spaces are blood-filled compartments within the corpus cavernosum which are drained by venules that coalesce into subtunical plexi which lie beneath the tunica albuginea [Keegan and Penson, 2013]. The tunica albuginea is a fibroelastic collagen-based structure which surrounds the corpora cavernosa [Keegan and Penson, 2013]; the collagen and fibroelastic fibres are arranged in an inner, circular layer and an outer, longitudinal layer [Goldstein and Padma-Nathan, 1990]. These fibroelastic properties allow for an increase in girth and elongation of the penis during tumescence, while also providing enough resilience for shrinkage to the flaccid state [Bitsch et al., 1990; Hsu et al., 1994; Iacono et al., 1995].

The subtunical plexi branch into emissary veins which penetrate the tunica albuginea [Keegan and Penson, 2013]. Superficial to the tunica albuginea, these veins drain into the deep dorsal vein or circumflex veins from the corpus spongiosum; the circumflex veins also ultimately drain into the deep dorsal vein (Fig. 1) [Quartey, 2006; Hsu et al., 2013].

Upon sexual stimulation, parasympathetic neural signals cause the smooth muscle surrounding the cavernous and helicine arteries to relax, leading to dilation of these blood vessels and thus increased blood flow into the erectile tissue [Kuno et al., 2001]. In addition, trabecular smooth muscle within the corpus cavernosum relaxes so that the sinusoidal spaces can expand following their engorgement of blood via the dilated arteries [Kuno et al., 2001]. The expanding sinusoids then compress the subtunical plexi against the unyielding tunica albuginea, occluding venous outflow of the penis [Keegan and Penson, 2013]. In addition, the pressure of the expanding sinusoids causes the tunica albuginea to stretch and compress the emissary veins, further restricting venous outflow [Panchatsharam et al., 2020]. Also, subtunical venules possess minimal geometric slack in the flaccid state (unlike the arteries and nerves), so when they elongate during tumescence, they subsequently narrow which further restricts outflow from the corpus cavernosum [Udelson et al., 2001]. This overall process is known as veno-occlusion, whereby blood inflow increases and blood outflow decreases, which in turn drastically increases the intracavernous pressure and results in tumescence.

Impacts of EDCs on Erectile Dysfunction
Complete veno-occlusion occurs when the engorged corpora cavernosa are compressed at their base by contraction of the ishiocavernosal muscles via somatic nerve stimulation [Edey et al., 2011]. Similarly, the bulbospongiosus muscle which surrounds the corpus cavernosum and spongiosum contracts to force additional blood into the penis during erection and compress the urethra to expel semen [Panchatsharam et al., 2020]. The corpus spongiosum also contains sinusoidal spaces which expand during erection and constrict the urethra to cause forceful ejaculation [Clement and Giuliano, 2015; Panchatsharam et al., 2020].

Upon sympathetic stimulation, the penile smooth muscle reverts to the contracted state, constricting the arterioles and sinusoidal spaces which in turn decompresses the penile veins [Andersson et al., 2000]. As a result, venous outflow increases which causes a reduction in intracavernous pressure, inducing detumescence.

Androgen signalling positively regulates smooth muscle content in the penis. Castration of rats, mice, rabbits, and dogs significantly reduces trabecular smooth muscle content accompanied by an increase in connective tissue [Takahashi et al., 1991; Shabsigh, 1997; Traish et al., 1999; Palese et al., 2003; Shen et al., 2003]. Furthermore, androgens stimulate the differentiation of mouse pluripotent mesenchymal cells into smooth muscle cells in vitro [Singh et al., 2003]. The smooth muscle content within the erectile tissue is correlated with the degree to which the corpus cavernosum can expand [Nehra et al., 1998]. Thus, the loss of smooth muscle induced by androgen deprivation is likely to disrupt erectile function. Indeed, several animal studies have shown that a loss of androgen signalling leads to attenuated erectile responses in vivo [Müller et al., 1988; Takahashi et al., 1991; Heaton and Varrin, 1994; Mills et al., 1994; Bivalacqua et al., 1998; Traish et al., 1999, 2003; Palese et al., 2003; Suzuki et al., 2007; Traish, 2009]. This is consistent with the reduction of penile smooth muscle content in patients with ED [Mersdorf et al., 1991; Claro et al., 2005] and those undergoing androgen deprivation [Tomada et al., 2013]. Interestingly, mice exposed to excess androgen levels also exhibit smooth muscle loss in the corpus cavernosa in vivo [Hiremath et al., 2020]. Therefore, a balance of androgen signalling maintains smooth muscle content (Fig. 2), which in turn promotes erectile function.

Androgen signalling also maintains the structural integrity of the tunica albuginea; castrated rats have reduced density of elastic fibres in the tunica albuginea which are replaced by collagen [Shen et al., 2003]. A reduction of elastic fibres may reduce the tunica albuginea's 
ability to expand, in turn disrupting veno-occlusion and causing ED [Akkus et al., 1997]. Indeed, rats with surgical injury to the tunica albuginea exhibit impaired erectile function following electric stimulation of the cavernous nerve [Bivalacqua et al., 2000]. Taken together, androgens also promote erectile function by maintaining the fibroelastic properties of the tunica albuginea.

Estrogen signalling within the vasculature of the erectile tissue may maintain the structural integrity of the endothelium, a key signalling centre for the regulation of vasodilation/vasorelaxation. Indeed, ER $\beta$ expression in the male rat aorta is increased in the endothelium and smooth muscle cells following vascular injury [Lindner et al., 1998]. In addition, estrogen signalling inhibits TNFaand oxidized low-density lipoprotein (oxLDL)-induced apoptosis of human endothelial cells in vitro [Spyridopoulos et al., 1997; Florian and Magder, 2008]. Furthermore, estrogen-mediated activation of Notch1 protects human umbilical vein endothelial cells from TNFainduced apoptosis in vitro [Fortini et al., 2017]. Interestingly, siRNA-knockdown of ER $\beta$, although not ERa, eliminated the anti-apoptotic effect of estrogen [Fortini et al., 2017].

Estrogen also increases the expression of $B c l 2$ and $B c l-X L$ in human endothelial cells in vitro, potentially generating a protective effect on this tissue [Florian and Magder, 2008]. Thus, estrogen signalling has a role in maintaining the structural integrity of the endothelium, although this has not yet been demonstrated in the penile endothelium. However, the expression of ERs within the vasculature of the rat penis raises this possibility [Jesmin et al., 2002].

\section{Calcium-Mediated Penile Smooth Muscle}

Contraction/Relaxation and RhoA/Rho Kinase-

Mediated Calcium Sensitisation

Smooth muscle contraction and relaxation is mediated by 2 critical proteins: myosin light chain kinase (MLCK) and myosin light chain phosphatase (MLCP). MLCK phosphorylates myosin light chains (MLCs), causing smooth muscle contraction [Kamm and Stull, 1985; Andersson, 2001]. Conversely, MLCP dephosphorylates MLCs, driving smooth muscle relaxation [Jin and Burnett, 2006]. In smooth muscle cells, cytosolic calcium ion $\left(\mathrm{Ca}^{2+}\right)$ concentrations regulate MLCK and MLCP activity which facilitates contraction and relaxation, respectively. Detumescence initiates with the increase in cytosolic $\mathrm{Ca}^{2+}$ concentrations of smooth muscle cells; $\mathrm{Ca}^{2+}$ then binds to calmodulin to form the Cam-Ca ${ }^{2+}$ complex which subsequently binds to and activates MLCK, leading to smooth muscle contraction [Andersson, 2001]. However, the rise in $\mathrm{Ca}^{2+}$ concentration is short-lived and quickly drops to baseline levels. Therefore, this process alone does not sustain chronic smooth muscle contraction required for the flaccid state [Mills et al., 2003; Hill-Eubanks et al., 2011].

To achieve this, the protein RhoA activates Rho-kinase, which in turn deactivates MLCP by phosphorylation. Since MLCP is deactivated and cannot dephosphorylate MLC and thus drive smooth muscle relaxation, the MLCs can stay phosphorylated at basal $\mathrm{Ca}^{2+}$, increasing $\mathrm{Ca}^{2+}$ sensitivity of smooth muscle cells [Mills et al., 2003]. $\mathrm{Ca}^{2+}$ sensitivity refers to the dependence of MLC phosphorylation on $\mathrm{Ca}^{2+}$ concentrations; sensitivity is high when small increases in $\mathrm{Ca}^{2+}$ drive a greater degree of MLC phosphorylation (as in the flaccid state). In contrast, low sensitivity occurs when larger increases in $\mathrm{Ca}^{2+}$ concentration are needed for a lesser degree of MLC phosphorylation, which is when MLCP actively dephosphorylates MLC [Rembold, 1992].

Inhibition of RhoA/Rho kinase-mediated calcium sensitization induces erectile activity in the rat, demonstrating the importance of this pathway in maintaining the flaccid state [Chitaley et al., 2001; Lasker et al., 2013]. Interestingly, RhoA expression is 17 -fold higher in the rabbit corpus cavernosum compared to the ileum smooth muscle, which is consistent with the chronic state of smooth muscle contraction in the corpus cavernosum compared to other parts of the vascular system [Wang et al., 2002].

Conversely, during tumescence, $\mathrm{Ca}^{2+}$ concentration in the smooth muscle cell drops so that MLCK cannot bind Cam- $\mathrm{Ca}^{2+}$ and induce contraction [Andersson, 2001]. However, reducing $\mathrm{Ca}^{2+}$ concentration is not sufficient to drive erection because the contractile machinery is sensitised to lower calcium concentrations through RhoA/ Rho-kinase inactivation of MLCP. Thus, inhibition of the RhoA/Rho kinase pathway must also occur so that MLCP can activate and dephosphorylate MLC, thereby decreasing $\mathrm{Ca}^{2+}$ sensitivity and driving smooth muscle relaxation [Mills et al., 2003]. In summary, detumescence and tumescence depend on a simple switch mechanism on whether MLC is phosphorylated (Fig. 3). However, the signalling pathways that regulate this switch by altering $\mathrm{Ca}^{2+}$ concentration and $\mathrm{Ca}^{2+}$ sensitivity in the smooth muscle cells of the erectile tissue are extremely complex.

\section{Nitric Oxide (NO)-cGMP Mediated Tumescence}

Nitric oxide (NO) is a non-noradrenergic, non-cholinergic (NANC) neurotransmitter and is essential for tumescence, as evidenced by several animal and human 
Fig. 3. MLCK and MLCP mediate smooth muscle contraction and relaxation, respectively [Mas, 2010]. $\mathrm{Ca}^{2+}$ ions bind to calmodulin to form the $\mathrm{Ca}^{2+}$-calmodulin complex (Cam-Ca) which then binds to and activates MLCK. Active MLCK phosphorylates MLC, facilitating smooth muscle contraction. Conversely, active MLCP dephosphorylates MLC, causing smooth muscle relaxation and tumescence. Active RhoA activates Rho kinase which deactivates MLCP by phosphorylation. Inactive RhoA allows for the activation of MLCP. Green refers to pathways driving tumescence, red refers to that of detumescence. MLCK, myosin light chain kinase; MLCP, myosin light chain phosphatase; MLC, myosin light chain; Cam-Ca, $\mathrm{Ca}^{2+}$-calmodulin complex; $\mathrm{P}$, phosphate group.

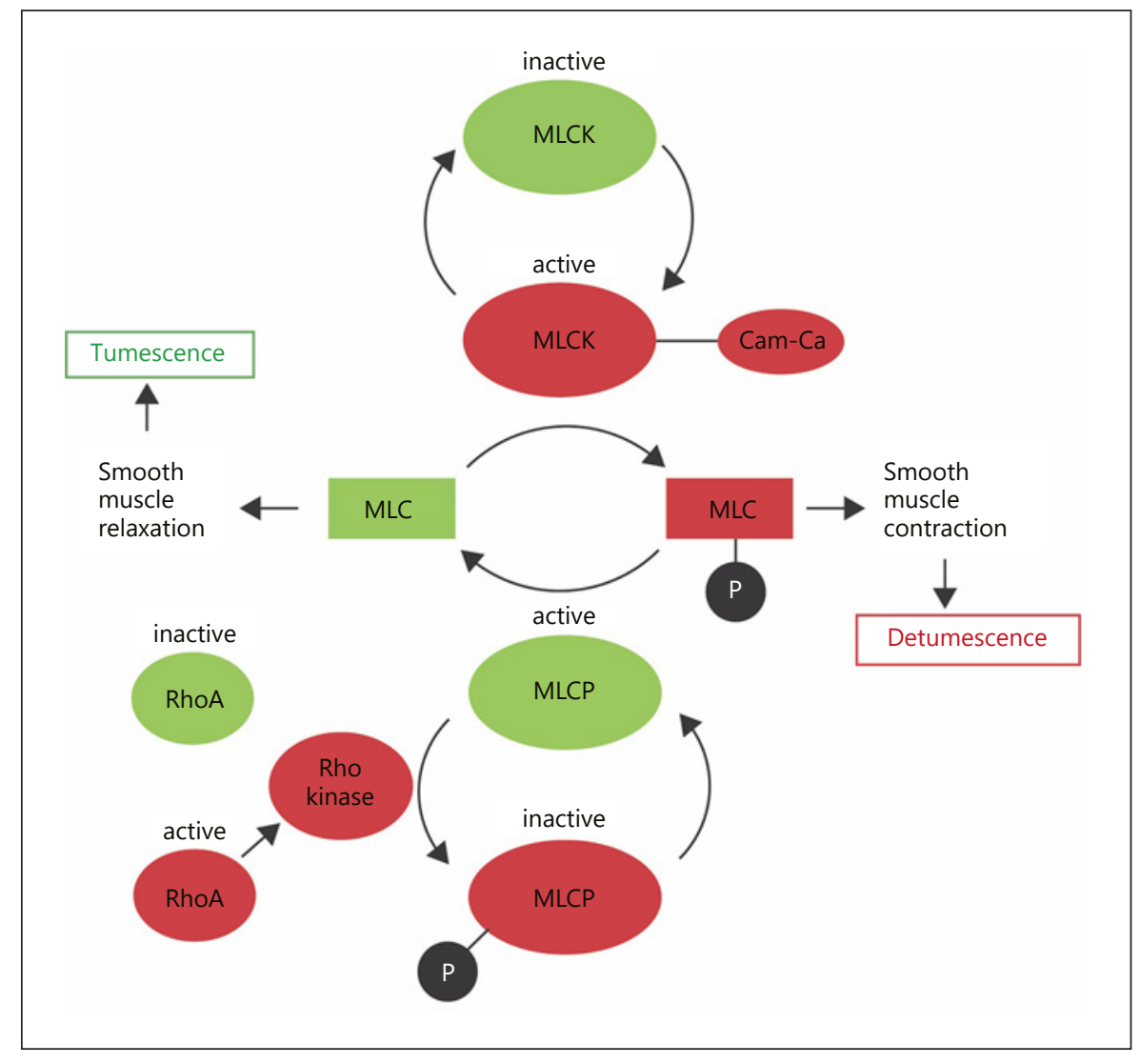

studies [Saenz de Tejada, 2002]. Upon parasympathetic stimulation, $\mathrm{NO}$ is released within the penis and activates soluble guanylyl cyclase which enhances production of cyclic guanosine monophosphate (cGMP). In turn, cGMP activates protein kinase $G(P K G)$ which reduces $\mathrm{Ca}^{2+}$ concentration through several mechanisms [Ghalayini, 2004; Krassioukov and Elliott, 2017]. This includes phosphorylation of $\mathrm{K}^{+}$channels, which leads to an efflux of $\mathrm{K}^{+}$ and subsequent hyperpolarization of smooth muscle cells within the penis [Archer, 2002]. Hyperpolarization closes voltage-dependent $\mathrm{Ca}^{2+}$ channels, thereby decreasing the influx of $\mathrm{Ca}^{2+}$ into smooth muscle cells [Andersson and Wagner, 1995]. In addition, PKG activates cation-ATPase pumps in the plasma membrane of smooth muscle cells and the sarcoplasmic reticulum, leading to $\mathrm{Ca}^{2+}$ efflux out of the cell and sequestration of $\mathrm{Ca}^{2+}$ in the sarcoplasmic reticulum, respectively (Fig. 4) [Lucas et al., 2000]. Activated PKG can also inhibit the inositol triphosphate 3 $\left(\mathrm{IP}_{3}\right)$ receptor, which blocks the influx of $\mathrm{Ca}^{2+}$ into the cytoplasm from the sarcoplasmic reticulum [Lucas et al., 2000].

Impacts of EDCs on Erectile Dysfunction
Hormonal signalling modulates cellular ion flux; testosterone treatment of human corpus cavernosum smooth muscle cells in vitro activates $\mathrm{K}^{+}$channels [Han et al., 2008]. Also, castration of rats leads to reduced levels of voltage-gated $\mathrm{Ca}^{2+}$ channels in the corpus cavernosum smooth muscle, thus androgen signalling positively correlates with voltage-gated $\mathrm{Ca}^{2+}$ channel expression (Fig. 2) [Luo et al., 2009]. In addition, rapid estrogen signalling via membrane-bound ERs (discussed below) is known to modulate intracellular $\mathrm{Ca}^{2+}$ [Zhang et al., 2009; Rainville et al., 2015; Puglisi et al., 2019]. Therefore, androgens and estrogens may have a role in regulating the ion flux of smooth muscle cells which is a critical component of tumescence. Indeed, androgen treatment was reported to induce rapid relaxation of human cavernosal arteries and corpus cavernosum in vitro, although this was not associated with increased levels of cGMP [Waldkirch et al., 2008], suggesting androgens can regulate ion channels via alternate mechanisms.

In addition to lowering cytosolic $\mathrm{Ca}^{2+}$ concentrations, the $\mathrm{NO} / \mathrm{cGMP} / \mathrm{PKG}$ pathway is thought to inhibit the RhoA/Rho-kinase pathway, allowing for the activation of 
Fig. 4. NO-cGMP mediated smooth muscle relaxation. Extracellular nitric oxide (NO) diffuses through the smooth muscle cell membrane and activates soluble guanylyl cyclase (sGC), producing cGMP as a result. This activates protein kinase $G$ (PKG) which then activates $\mathrm{K}^{+}$channels causing an efflux of $\mathrm{K}^{+}$from the cell. This results in hyperpolarization (HP) which blocks $\mathrm{Ca}^{2+}$ channels so $\mathrm{Ca}^{2+}$ influx is reduced. In addition, PKG also activates cation ATPase pumps in the cell membrane and sarcoplasmic reticulum (SR), driving an efflux of $\mathrm{Ca}^{2+}$ out of the cell and sequestration of $\mathrm{Ca}^{2+}$ in the $\mathrm{SR}$, respectively. PKG also suppresses the RhoA/Rho-kinase pathway, thereby decreasing $\mathrm{Ca}^{2+}$ sensitivity. NO-mediated reduction in cytosolic $\mathrm{Ca}^{2+}$ and increased $\mathrm{Ca}^{2+}$ sensitivity drives relaxation of the smooth muscle cell. The phosphodiesterase proteins (PDEs) break down cGMP.

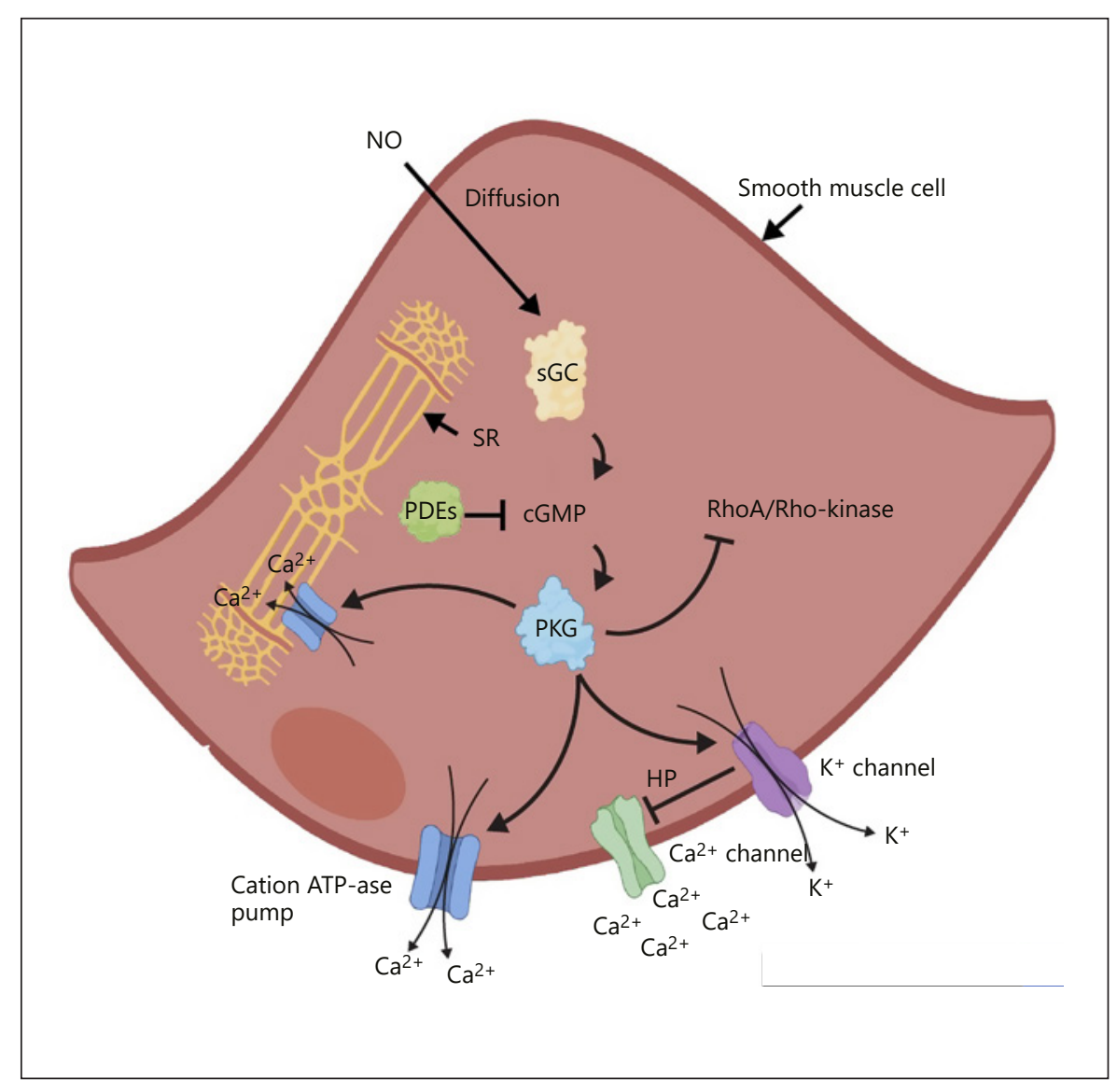

MLCP which is essential for tumescence (Fig. 4) [Mills et al., 2003]. This is consistent with rodent studies which disrupt the NO/cGMP/cGMP pathway: in vitro organ bath experiments show that the corpus cavernosum of PKG-null mice have diminished smooth muscle relaxation [Hedlund et al., 2000]. Also, inhibition of guanylyl cyclase in the corpus cavernosum of rats in vivo significantly reduces the erectile response after electrostimulation of the cavernous nerve [Martinez-Piñeiro et al., 1993]. The disrupted erectile responses observed in these studies are likely due to the RhoA/Rho-kinase pathway remaining active. Furthermore, PKG inhibits $\mathrm{Ca}^{2+}$ sensitization induced by RhoA in rat aortic smooth muscle cells in vitro by phosphorylation of RhoA [Sauzeau et al., 2000]. However, a direct effect of PKG on RhoA specifically in penile smooth muscle has not yet been proven. $\mathrm{NO} / \mathrm{cGMP}$ signalling is also considered the primary pathway for increasing blood flow into the clitoris and vagina during sexual arousal [Giuliano et al., 2002]. Thus, sexual function in the female and male genitalia arise from similar molecular pathways.
The phosphodiesterase (PDE) protein family inhibits tumescence by breaking down secondary messenger molecules such as cGMP and cAMP (discussed below) (Fig. 4) [Turko et al., 1999]. Interestingly, PDE5 (which breaks down cGMP) mRNA is present in the human corpus cavernosum at levels 10- to 100-fold higher compared to other non-reproductive tissues in males [Morelli et al., 2004]. Alongside higher levels of RhoA in the corpus cavernosum, this likely serves to maintain the penis in a chronically contracted state to maintain flaccidity.

Androgen signalling is thought to upregulate PDE5 expression; castrated rabbits and rats display reduced PDE5 expression and activity, which is restored by testosterone replacement [Morelli et al., 2004; Zhang et al., 2005; Armagan et al., 2006]. Also, transsexual individuals in a hypogonadal state also exhibit decreased PDE5 expression and activity in the corpus cavernosum [Morelli et al., 2004]. In addition, treatment with a PDE5 inhibitor alone has little effect on the erectile function of castrated animals, demonstrating that PDE5 expression relies on androgen signalling [Traish et al., 2003; Zhang et al., 2005]. 
Fig. 5. Estrogen-mediated positive regulation of eNOS expression/activation. In the endothelial cell, when the estrogen receptor (ER) binds to the estrogen ligand (endogenous or exogenous estrogen or estrogen-mimicking EDCs; green circle), it dimerises and translocates to the nucleus where it binds to an estrogen-response element (ERE) in the NOS3 promoter. This induces transcription of NOS3 which leads to production of endothelial nitric oxide synthase (eNOS). In addition, the association of membrane-bound estrogen receptors (mERs) with estrogen initiates rapid, non-genomic signalling. This involves activation of the phosphoinositide 3-kinase/ protein kinase B (PI3K/Akt) pathway, which in turn activates eNOS by phosphorylation so that it produces NO. NO is the same as shown in Figure 4.

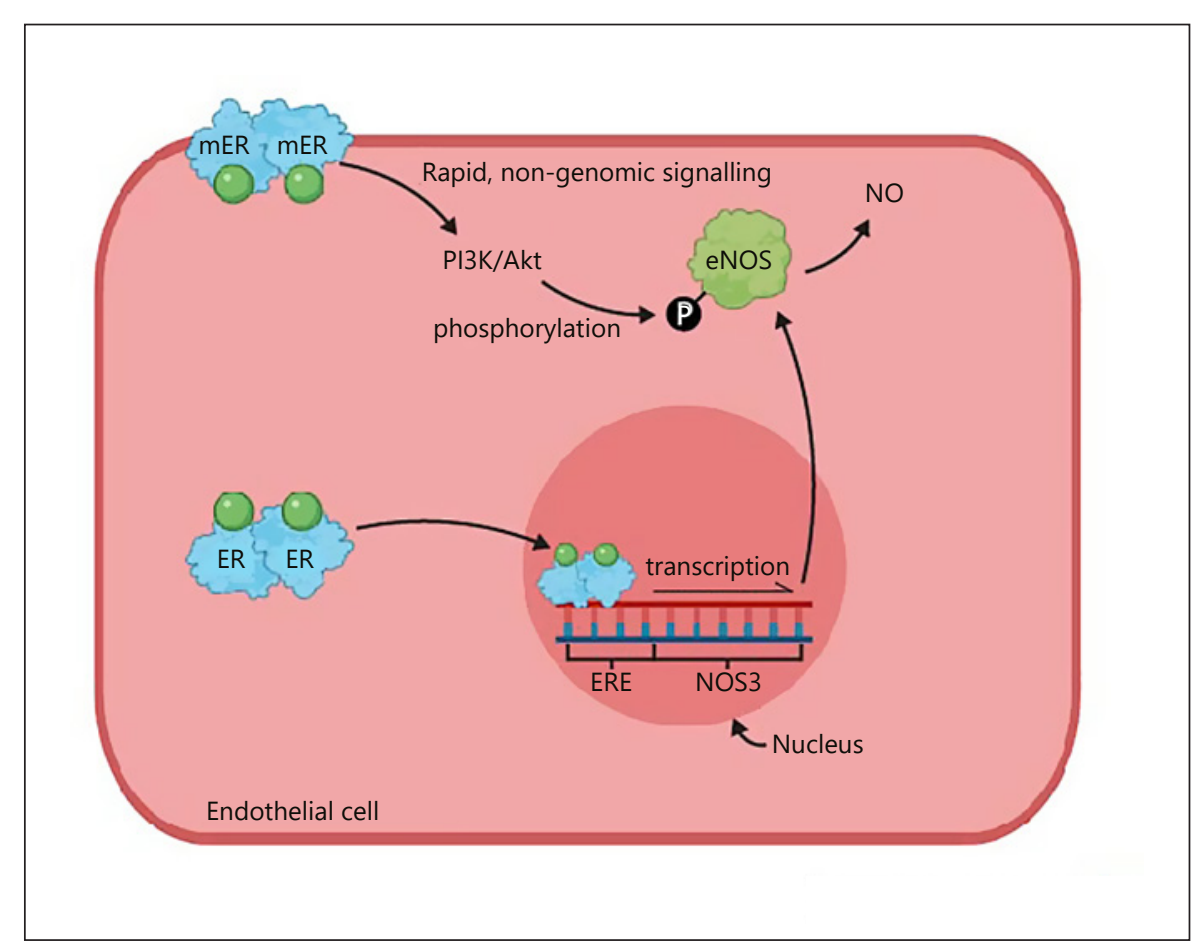

However, androgens have no effect on PDE5 expression in cavernous smooth muscle cells in vitro, suggesting an indirect effect of androgens on PDE5 expression in vivo [Yang et al., 2009]. This is supported by the fact that no androgen response element has been found in the rat Pde5a gene [Lin et al., 2013] and that genome-wide searches for genes regulated by androgens in human cells did not yield PDE5A as a candidate [Bolton et al., 2007; Massie et al., 2007]. Rather than directly upregulating PDE5, androgens may provide the cellular context for PDE5 expression in the smooth muscle as these hormones are critical for the development and maintenance of vasculature within the erectile tissue (Fig. 2). Indeed, castration of rats leads to the simultaneous reduction of cavernous smooth muscle and PDE5 expression [Liu et al., 2005; Yang et al., 2009].

\section{NO Production by Activation of Nitric Oxide Synthase Isoforms}

NO in the penis is derived from 2 main sources: NANC parasympathetic nerves and the endothelium lining blood vessels and sinusoids [Cartledge et al., 2001]. This is evident by the spatial expression of the nitric oxide synthase (NOS) enzymes, of which there are several isoforms that differ in tissue distribution. The neuronal NOS (nNOS) isoform is localised within penile nerve cells in rodents and humans [Gonzalez-Cadavid et al., 2000; Dashwood et al., 2011], and the endothelial NOS (eNOS) isoform is expressed in the endothelium of the mouse and human erectile tissues (Fig. 5, 6) [Burnett et al., 1996; Seftel et al., 1997]. Although the NOS enzymes are referred to as isoforms, they are encoded by separate genes and not splice variants from a single gene [Huang et al., 1993].

Upon sexual stimulation of the parasympathetic system, NANC nerves within the penis depolarize via an influx of $\mathrm{Ca}^{2+}$ which then forms the Cam- $\mathrm{Ca}^{2+}$ complex, activating nNOS [Bredt and Snyder, 1990]. As a result, nNOS produces NO which relaxes smooth muscles, thereby dilating penile blood vessels and initiating the erectile response. Despite this, nerve cell depolarization via $\mathrm{Ca}^{2+}$ influx is transitory and nNOS quickly deactivates, thus relaxing smooth muscles only briefly [Hurt et al., 2012]. However, this initial increase in blood flow and shear stress on the endothelium activates phosphoinositide 3-kinase (PI3K) which stimulates protein kinase B (Akt), in turn activating eNOS by phosphorylation (Fig. 6) [Hurt et al., 2002; Musicki et al., 2005; Wen et al., 2011]. Phosphorylation activates NOS considerably longer than by depolarization, and thus phosphorylated eNOS can continually produce NO to sustain smooth muscle relaxation (Fig. 6) [Hurt et al., 2012]. 


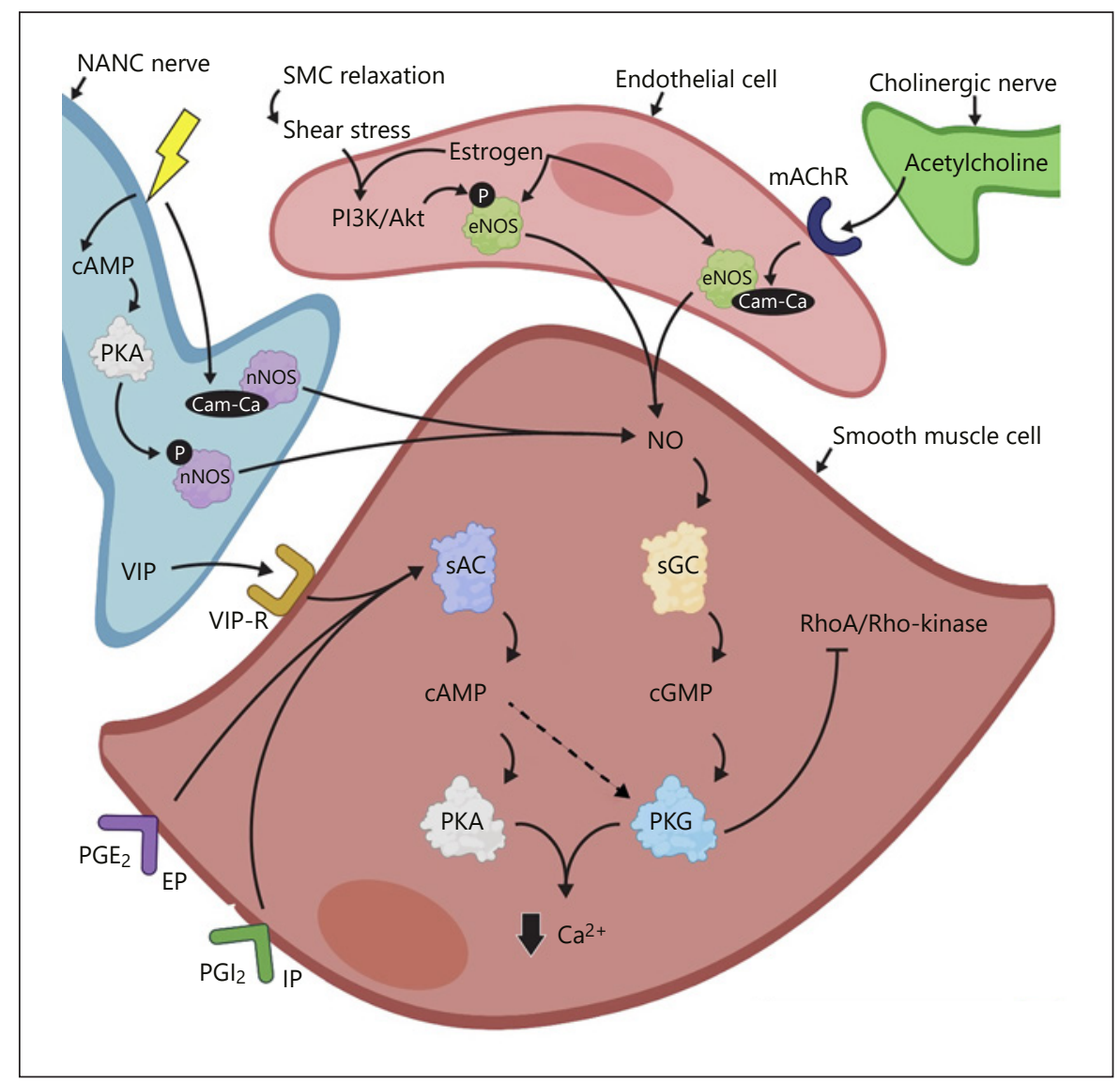

Fig. 6. NO sources and other factors which drive smooth muscle relaxation. The NO-cGMP pathway reduces cytosolic $\mathrm{Ca}^{2+}$ and inhibits the RhoA/Rho-kinase pathway as depicted in Figure 4. When the NANC nerves are stimulated (lightning bolt), $\mathrm{Ca}^{2+}$ binds to calmodulin to form the calmodulin- $\mathrm{Ca}^{2+}\left(\mathrm{Cam}-\mathrm{Ca}^{2+}\right)$ complex. This subsequently binds to and activates neuronal NOS (nNOS), driving NO production. Also, stimulation of NANC nerves drives production of cAMP in these cells. This activates protein kinase A (PKA) which in turn activates nNOS by phosphorylation $(\mathrm{P})$. The initial production of NO by the NANC nerves leads to smooth muscle cell (SMC) relaxation, in turn leading to shear stress on the endothelial cells. This triggers the PI3K/Akt pathway, which then activates eNOS by phosphorylation. Acetylcholine released from cholinergic nerves binds to the muscarinic acetylcholine receptor (mAChR), which increases $\mathrm{Ca}^{2+}$ in the en-

In addition, sexual stimulation increases production of cyclic adenosine monophosphate (cAMP) (discussed further below), which activates protein kinase A (PKA). In turn, PKA phosphorylates nNOS so it also continually produces NO (Fig. 6) [Hurt et al., 2012]. These findings demonstrate that while nNOS initiates NO-mediated erection upon parasympathetic stimulation, both $\mathrm{nNOS}$ and eNOS sustain erection via their phosphorylated state dothelial cell. This leads to formation of Cam- $\mathrm{Ca}^{2+}$, which binds to and activates eNOS. Endogenous estrogen signalling also activates eNOS by stimulating the PI3K/Akt pathway and upregulates expression of eNOS (see Fig. 5). In addition to the NO-cGMP pathway, vasoactive intestinal peptide (VIP) in the NANC nerves may bind to its receptor (VIP-R) on the smooth muscle cell to stimulate soluble adenylyl cyclase (sAC). This leads to production of cAMP in the smooth muscle cell, activating PKA to reduce cytosolic $\mathrm{Ca}^{2+}$ concentration. cAMP may also mediate smooth muscle cell relaxation via activation of PKG. The prostanoids prostaglandin $\mathrm{E}_{2}$ $\left(\mathrm{PGE}_{2}\right)$ and prostacyclin $\left(\mathrm{PGI}_{2}\right)$ can also drive cAMP production via association with the EP and IP receptors on the smooth muscle cell, respectively. NANC is the same as shown in Figure $2 s G C, P K G$ and $N O$ are the same as shown in Figure 4. PI3K/Akt and eNOS are the same as shown in Figure 5. 
signalling is associated with increased NOS activity/expression in the erectile tissue and nerves innervating the penis [Lugg et al., 1995; Penson et al., 1996; Reilly et al., 1997; Schirar et al., 1997; Marin et al., 1999; Park et al., 1999; Seo et al., 1999; Armagan et al., 2006]. However, androgen deprivation was found to increase eNOS mRNA and have no effect on nNOS mRNA levels in rat erectile tissue [Shen et al., 2000a]. Furthermore, androgen withdrawal was reported to increase eNOS levels in the human corpus cavernosum [Tomada et al., 2013]. The conflicting data suggests that a precisely controlled balance of androgen signalling is required for maintaining normal levels of NOS expression and activity (Fig. 2). Also, cGMP can stimulate expression of the human PDE5A gene [Lin et al., 2001, 2006]. Thus, androgens may indirectly upregulate PDE5 via positive regulation of the NOS enzymes which in turn drives cGMP production.

Estrogen signalling may also promote smooth muscle relaxation by stimulating NOS expression and activity in the erectile tissue. Indeed, in humans and animals, ERs upregulate eNOS via an estrogen-response element in the eNOS promoter (Fig. 5) [MacRitchie et al., 1997; Yang et al., 2000; McNeill Anne et al., 2002; Min, 2007]. Interestingly, in human endothelial cell cultures, activated membrane-bound ERs rapidly stimulate the PI3K/Akt pathway via a non-genomic mechanism, which in turn activates eNOS by phosphorylation (Fig. 5, 6) [Haynes et al., $2000,2003]$. This is consistent with the significantly higher basal release of endothelium-derived $\mathrm{NO}$ in the male mouse aorta compared to that of the male estrogen receptor knockout (ERKO) mouse, suggesting that ER levels are related to basal NO production in endothelium [Rubanyi et al., 1997].

Furthermore, estrogen-deficient post-menopausal women have reduced levels of ERa, eNOS, and phosphorylated eNOS in endothelial cells of the antecubital vein compared to premenopausal women [Gavin et al., 2009]. Postmenopausal women also display reduced endothelial-dependent dilation of the brachial artery, suggesting that a loss of estrogen leads to a reduction in NO bioavailability [Gavin et al., 2009]. Taken together, estrogen signalling in the endothelium can upregulate and activate eNOS via genomic and non-genomic mechanisms, respectively.

Estrogen may also promote tumescence by positively regulating $\mathrm{nNOS}$ activity/expression. The treatment of human nNOS-expressing neuroblastoma cell lines with estrogen was reported to cause a rapid increase in $\mathrm{NO}$ production via activation of eNOS and nNOS in vitro [Wen et al., 2004; Xia and Krukoff, 2004]. Also, the injec-

Impacts of EDCs on Erectile Dysfunction tion of estrogen into ovariectomized rats increases $\mathrm{nNOS}$ mRNA in the hypothalamus and hippocampus [Ceccatelli et al., 1996; Grohe et al., 2004]. The stimulation of neuronal NO production by estrogen may also explain the neuroprotective properties of estrogen as NO is a known neuroprotective agent [Chiueh, 1999; Wen et al., 2004]. Thus, estrogen signalling may positively regulate nNOS in nerves innervating the erectile tissue. However, to the best of our knowledge this remains to be proven.

\section{Disruptions of NO-cGMP Pathway and Compensatory Mechanisms}

The NO-cGMP pathway has a profound impact on tumescence, and compensatory mechanisms exist if it is disrupted. For example, mice with a mutation for $\mathrm{nNOS}$ display normal mating behaviour and erectile function; eNOS is upregulated in these mice which may compensate for disrupted NO production [Burnett et al., 1996]. Although eNOS is defined by its localisation to the endothelium, it may also localize to neural cells within the penis, potentially substituting the function of nNOS [Cashen et al., 2002]. This remains to be proven, although eNOS is localised in the dendritic spines of primary culture cortical and hippocampal neurons from rats at embryonic day 18 [Caviedes et al., 2017].

Mice with mutations for eNOS also display normal erectile function and retain about $60 \%$ of the NOS activity in the penis compared to that of WT mice [Burnett et al., 2002]. This shows that other NOS isoforms synthesise $\mathrm{NO}$ in mice lacking eNOS, compensating for erectile function [Burnett et al., 2002]. In addition, although $\mathrm{nNOS}$ is defined by its neuronal localization, its expression in endothelial cells within the penis may also compensate for a loss of eNOS [Cashen et al., 2002]. This is reinforced by the co-expression of nNOS with eNOS in the human umbilical vein endothelial cells in vitro [Bachetti et al., 2004].

Overall, the activity of NOS isoforms can compensate for each other if one is mutated, thereby allowing for tumescence despite disruption of the NO-cGMP pathway. Further compensation may arise by potential overlap of eNOS and nNOS localisation in the erectile tissue.

\section{Additional Pro-Erectile Signalling Pathways}

While parasympathetic signalling mediated by the NO-cGMP pathway is primarily responsible for tumescence, other signalling pathways modulate erectile function through stimulation of cGMP and cAMP production. These factors may also compensate for deficiencies in NO-signalling, potentially explaining normal erectile 
function in NOS mutant mice from the studies mentioned above.

\section{cAMP/PKA Pathway}

The second messenger cAMP is produced by adenylyl cyclase and activates PKA [Sassone-Corsi, 2012]. In addition to cGMP signalling, cAMP/PKA signalling is thought to mediate smooth muscle relaxation in the penis. Indeed, several studies have identified cAMP signalling in the corpus cavernosum smooth muscle [Lin et al., 2005]. In addition, forskolin (adenylyl cyclase activator) administration relaxes the human corpus cavernosum in vitro; the magnitude of relaxation correlates with the level of cAMP accumulation induced by forskolin in human corporal smooth muscle cells in vitro [Palmer et al., 1994]. The mechanism by which cAMP/PKA signalling relaxes penile smooth muscle cells likely involves the activation of $\mathrm{K}^{+}$channels on the smooth muscle cell membrane, hyperpolarizing the smooth muscle cell and thereby decreasing cytosolic $\mathrm{Ca}^{2+}$ levels. This is illustrated by the ablation of $\mathrm{PGE}_{1}$ (a relaxing factor discussed below) induced activation of $\mathrm{K}^{+}$channels in human corporal smooth muscle cells in vitro by a PKA inhibitor [Lee et al., 1999].

In contrast, the treatment of rats with an adenylyl cyclase inhibitor does not affect the erectile response in vivo following electrostimulation of the cavernous nerve [Martinez-Piñeiro et al., 1993]. There is also little evidence to suggest that the cAMP/PKA pathway reduces $\mathrm{Ca}^{2+}$ sensitivity to the contractile machinery in penile smooth muscle through inhibition of the RhoA/Rho-kinase pathway, a critical component for tumescence. Therefore, it is likely that the NO/cGMP/PKG pathway is the key driver for tumescence while cAMP/PKA signalling has a relatively minor role by reducing cytosolic $\mathrm{Ca}^{2+}$ concentration (Fig. 6).

Importantly, these pathways are not mutually exclusive; crosstalk exists between cAMP and cGMP signalling. This is partially discussed above with cAMP/PKAmediated phosphorylation of nNOS. In addition, both cAMP and cGMP can activate PKG in cavernosal smooth muscle cell cultures from young (16 weeks) and old (28 months) rats [Lin et al., 2002]. Therefore, while activation of the cAMP pathway may have minor direct effects on tumescence, it may also indirectly contribute to it by reinforcing the cGMP/PKG-signalling pathway (Fig. 6).

Vasoactive Intestinal Peptide

Before NO-cGMP signalling was established as the key pathway for tumescence, considerable attention was giv- en to the relaxant effects of vasoactive intestinal peptide (VIP) in this process. Nerves innervating the erectile tissue in humans and rabbits contain VIP, and thus it may function as a neurotransmitter in the penis to promote tumescence [Polak et al., 1981; Willis et al., 1983]. This is supported by the presence of VIP receptors in smooth muscle cells of the rat corpus cavernosum in vitro [Guidone et al., 2002]. Furthermore, administration of a VIPantagonist to the rabbit corpus cavernosum reduces relaxation in vitro following electric stimuli [Kim et al., 1995] and also to the rat penis in vivo following cavernous nerve stimulation [Suh et al., 1995]. In addition, tumescence is associated with increased VIP concentration in the cavernous blood in humans, and administration of VIP drives erection [Ottesen et al., 1984]. The mechanism of VIP-mediated tumescence most likely involves elevating cAMP levels in smooth muscle cells of the erectile tissue; VIP dose-dependently induces production of cAMP in rat corpus cavernosum smooth muscle cells [Guidone et al., 2002].

However, VIP is not the primary relaxant agent in tumescence: injection of VIP into the rat penis enhances erection in vivo but does not induce a full erection [Suh et al., 1995]. Also, electrical field stimulation-induced relaxation of the human corpus cavernosum in vitro is not diminished by VIP inactivation [Pickard et al., 1993]. For a rigid erection sufficient for penetration, it is likely that VIP functions alongside other pro-erectile pathways. Indeed, VIP and NOS are colocalised in nerves innervating the erectile tissue in animals and humans, suggesting that NO and VIP complement each other to facilitate erectile activity (Fig. 6) [Ehmke et al., 1995; Andersson, 2001]. This is supported by injection of a combination of VIP and SIN-1 (NO-releasing compound) into the rabbit corpus cavernosum which augments the erectile response in vivo compared to those injected with SIN-1 or VIP alone, revealing an additive effect of the NO and VIP pathways [Sazova et al., 2002]. Overall, VIP is indisputably a smooth muscle relaxant and most likely complements NO-cGMP signalling via the cAMP pathway to promote tumescence (Fig. 6).

VIP signalling appears to be independent of androgen signalling; men with chemical castration display no significant change in VIP levels in the corpus cavernosum compared to non-castrated individuals [Cormio et al., 2005]. Also, castrated rats display no significant change of VIP mRNA levels in the corpus cavernosum [Shen et al., 2000b]. However, the erectile function of castrated rats display greater responsiveness to VIP, suggesting that androgens negatively regulate the VIP/cAMP pathway [Zhang et al., 2011]. 


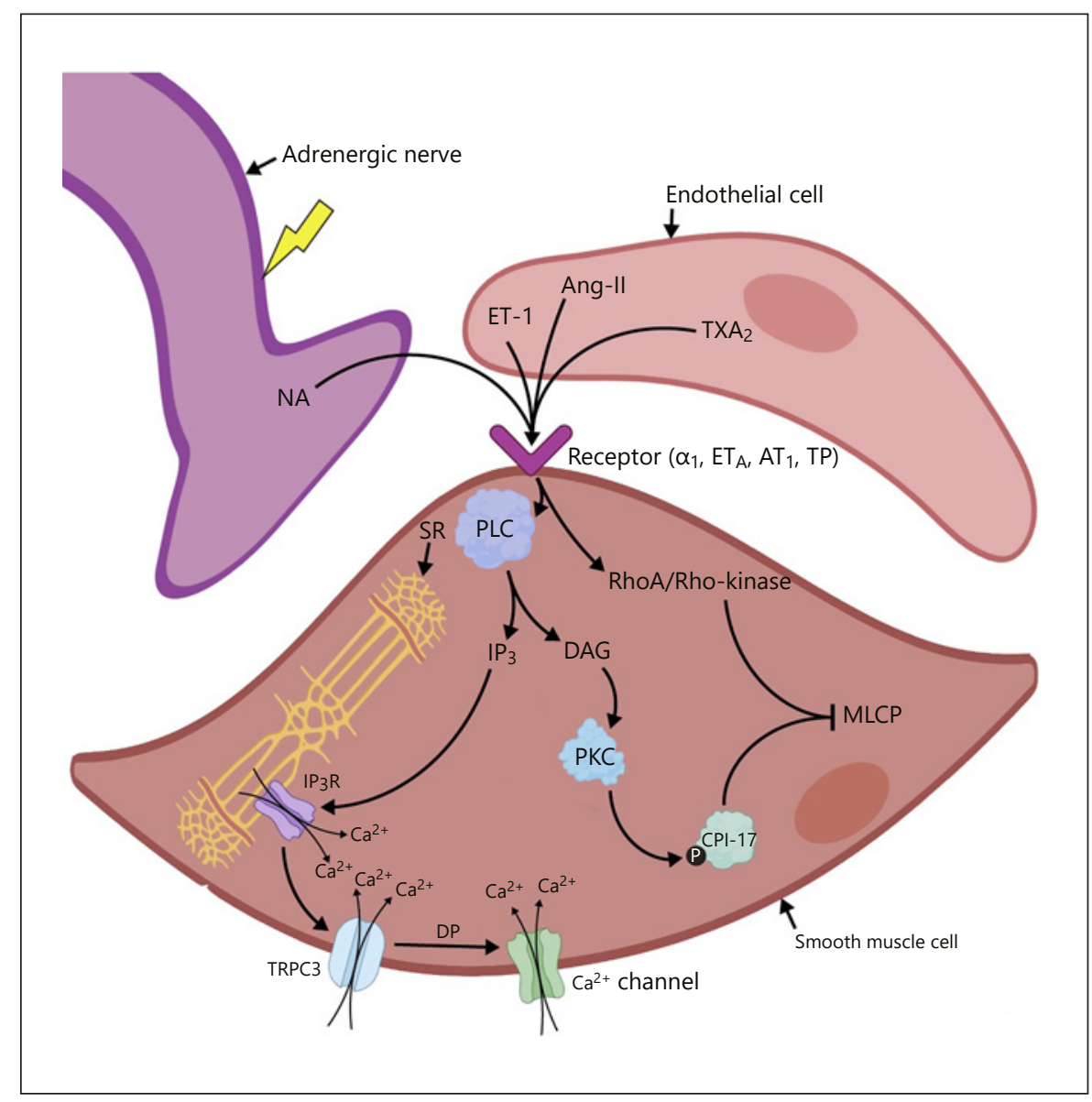

Fig. 7. Smooth muscle contraction pathways. Upon stimulation of adrenergic nerves (lightning bolt), noradrenaline (NA) is released and binds to the $\alpha_{1}$-adrenoreceptor $\left(\alpha_{1}\right)$. Endothelin-1 (ET-1), angiotensin-II (Ang-II), and the prostanoid thromboxane $\mathrm{A}_{2}\left(\mathrm{TXA}_{2}\right)$ released from the endothelial cell bind to their receptors $\mathrm{ET}_{\mathrm{A}}, \mathrm{AT}_{1}$, and TP, respectively, on the smooth muscle cell. Association of these ligands with their receptors leads to activation of phospholipase C (PLC), which then produces inositol triphosphate $3\left(\mathrm{IP}_{3}\right)$ and diacylglycerol (DAG). $\mathrm{IP}_{3}$ associates with the $\mathrm{IP}_{3}$ receptor $\left(\mathrm{IP}_{3} \mathrm{R}\right)$ on the sarcoplasmic reticulum (SR), which acts as a channel to release $\mathrm{Ca}^{2+}$ from the SR. The activated $\mathrm{IP}_{3} \mathrm{R}$ s couple with membrane-bound transient receptor potential canonical 3 (TRPC3)

\section{Prostanoids (Involved in Tumescence and}

Detumescence)

Prostanoid metabolites are produced via several synthases from arachidonic acid in the endothelium [Minhas et al., 2000]. The prostanoid metabolites identified in the human and animal corpus cavernosum are the prostaglandins $\left(\mathrm{PGI}_{2}, \mathrm{PGF}_{2 \alpha}, \mathrm{PGE}_{2}, \mathrm{PGD}_{2}\right)$ and thromboxane $\mathrm{A}_{2}\left(\mathrm{TXA}_{2}\right)$ [Khan et al., 1999; Andersson, 2011]; these mediate their functions via the IP, FP, EP, DP, and TP receptors, respectively (Fig. 6, 7) [Andersson, 2011]. The channels, leading to an influx of extracellular $\mathrm{Ca}^{2+}$. Increased cytosolic $\mathrm{Ca}^{2+}$ in the smooth muscle cell causes depolarization (DP), activating $\mathrm{Ca}^{2+}$ channels in the smooth muscle cell membrane which leads to a further influx of $\mathrm{Ca}^{2+}$. DAG leads to activation of protein kinase $\mathrm{C}(\mathrm{PKC})$, which activates CPI-17 by phosphorylation. This then inhibits MLCP. Association of NA, $\mathrm{ET}_{\mathrm{A}}$, Ang-II, and $\mathrm{TXA}_{2}$ with their receptors may also drive the RhoA/Rho-kinase pathway to inhibit MLCP. Thus, these signalling factors drive smooth muscle cell contraction by increasing cytosolic $\mathrm{Ca}^{2+}$ and increasing $\mathrm{Ca}^{2+}$ sensitivity. MLCP is the same as shown in Figure 3.

prostanoids exert dual functions on erectile function as some contract or relax penile smooth muscle: administration of a TP receptor agonist and $\mathrm{PGF}_{2 \alpha}$ to isolated human corpus cavernosum preparations results in contraction [Hedlund and Andersson, 1985b]. On the other hand, treatment with $\mathrm{PGE}_{2}$ and $\mathrm{PGE}_{1}$ leads to relaxation [Hedlund and Andersson, 1985b].

Prostanoid-induced relaxation is supported by studies which show that injection of $\mathrm{PGE}_{1}$ leads to relaxation of the monkey [Bosch et al., 1989] and rat corpus caverno- 
sum in vivo [Chen et al., 1992]. In addition, the EP receptors are known to mediate $\mathrm{PGE}_{1}$ - and $\mathrm{PGE}_{2}$-induced relaxation of the human corpus cavernosum in vitro [Angulo et al., 2002]. In fact, the documented relaxant effects of $\mathrm{PGE}_{1}$ has led to its use as a treatment for ED and results in greater satisfaction in sexual performance [Linet and Neff, 1994; Urciuoli et al., 2004]. Prostanoids may contribute to tumescence by stimulating cAMP production; $\mathrm{G}_{\mathrm{s}}$-protein coupled EP and IP receptors (for $\mathrm{PGE}_{2}$ and $\mathrm{PGI}_{2}$ ) are known to stimulate adenylyl cyclase (Fig. 6) [Ricciotti and FitzGerald, 2011]. This is supported by $\mathrm{PGE}_{1}$ administration in combination with an inhibitor of a cAMP-specific PDE which leads to relaxation and increased cAMP levels in primary culture human cavernosal smooth muscle cells [Bivalacqua et al., 1999]. Furthermore, in equine penile arteries, treatment of a PKA inhibitor decreases the relaxant effects of $\mathrm{PGE}_{1}$, demonstrating that this prostaglandin relaxes penile blood vessels via the cAMP/PKA pathway [Ruiz Rubio et al., 2004].

Interestingly, treatment of rats with $\mathrm{PGE}_{1}$ dose-dependently increases NO production and increases $\mathrm{n} /$ eNOS expression in the rat corpus cavernosum in vivo, revealing that $\mathrm{PGE}_{1}$ may also relax erectile tissue through the NO-cGMP pathway [Escrig et al., 1999]. This contradicts the finding that inhibition of NOS did not affect $\mathrm{PGE}_{1}$-mediated relaxation of equine penile arteries in vitro [Ruiz Rubio et al., 2004]. However, the same authors demonstrated that the combined inhibition of PKA and $P K G$ reduced $\mathrm{PGE}_{1}$-mediated relaxation, suggesting $\mathrm{PGE}_{1}$ primarily influences cAMP signalling and potentially the cGMP pathway. It should be noted that to the best of our knowledge, $\mathrm{PGE}_{1}$ has not been identified as a naturally occurring prostaglandin in the penis. Thus, the relaxant effects of $\mathrm{PGE}_{1}$ described above do not necessarily reflect that of the native prostaglandins.

In contrast to relaxant prostanoids, the $\mathrm{TP}$ receptor (for $\mathrm{TXA}_{2}$ ) can activate phospholipase C (PLC), an enzyme which hydrolyses phosphatidylinositol 4,5-biphosphate $\left(\mathrm{PIP}_{2}\right)$ into diacylglycerol (DAG) and $\mathrm{IP}_{3}$, intracellular messengers which increase cytosolic $\mathrm{Ca}^{2+}$ concentration (discussed further below) (Fig. 7) [Feletou, 2010]. In addition, the $\mathrm{TP}$ receptor can activate $\mathrm{Rho}_{\mathrm{GEF}}$, which in turn activates RhoA [Feletou, 2010]. Thus, TXA through its receptor may drive smooth muscle contraction in the penis by elevating cytosolic $\mathrm{Ca}^{2+}$ and promoting the RhoA/Rho-kinase pathway (Fig. 7). Indeed, TP receptors are identified as contractile factors of human penile arteries and trabecular smooth muscle in vitro [Angulo et al., 2002]. Also, treatment of rat cavernous arteries with the TXA 2 analogue U46619 led to increased
$\mathrm{Ca}^{2+}$ concentration and contraction in vitro [Grann et al., 2016]. The authors also found that treatment of the Rhokinase inhibitors Y27632 and glycyl-H1152P dose-dependently attenuated U46619-induced contraction, providing further evidence that $\mathrm{TXA}_{2}$ mediates contraction via activating the RhoA/Rho-kinase pathway. DP receptors (for $\mathrm{PGF}_{2 \alpha}$ ) can also increase $\mathrm{Ca}^{2+}$ concentration and inhibit production of cAMP, potentially explaining its contractile properties in the penis [Ricciotti and FitzGerald, 2011].

Contradictory findings have been reported on the effects of $\mathrm{PGI}_{2}$ on penile smooth muscle: $\mathrm{PGI}_{2}$ treatment to isolated human corpus cavernosum was reported to cause contraction [Hedlund and Andersson, 1985b], while a separate study found that treatment of iloprost $\left(\mathrm{PGI}_{2}\right.$ analogue) to isolated rat corpus cavernosum leads to relaxation [Bassiouni et al., 2019]. Another study found that $\mathrm{PGI}_{2}$ relaxed 4 of 6 isolated human corpus cavernosum samples but had no effect on the remaining 2 [Kirkeby et al., 1993]. Thus, it is unclear from these results as to whether $\mathrm{PGI}_{2}$ has a contractile, relaxant, or neutral effect on smooth muscle cells in the corpus cavernosum.

This is unexpected as $\mathrm{PGI}_{2}$ is an established vasodilator in blood vessels. Lue [2011] suggests that this discrepancy arises from varying distribution of IP receptors (for $\mathrm{PGI}_{2}$ ) within the penis. Indeed, it is unlikely the IP receptor is present in trabecular smooth muscle because $\mathrm{PGI}_{2}$ fails to relax trabecular smooth muscle in human corpus cavernosum in vitro [Angulo et al., 2002]. However, $\mathrm{PGI}_{2}$ is a potent vasodilator in human penile arteries in vitro, which is confirmed by the presence of IP receptors in this tissue [Angulo et al., 2002]. Thus, the specific distribution of prostanoid receptors in the vascular bed of the penis can coordinate the effects of prostanoids on smooth muscle relaxation.

Taken together, prostanoid signalling relaxes and contracts penile smooth muscle, thus contributing to tumescence and detumescence, respectively (Fig. 6, 7).

Interestingly, in addition to the role that prostanoids have in erectile physiology, the mechanism by which androgens masculinize mouse embryos involves the arachidonic acid cascade which leads to prostaglandins [Gupta and Goldman, 1986]. Thus, androgen-mediated prostanoid signalling may also drive development of the erectile tissue, although more research is required to elucidate this.

\section{Acetylcholine}

In addition to NANC nerves which release NO, the mammal penis is also innervated by cholinergic nerves 
which release acetylcholine to drive erection (Fig. 6) [Andersson, 2001]. This is further supported by the high density of acetylcholinesterase (which breaks down acetylcholine) in the monkey corpus cavernosum [Stief et al., 1989]. Acetylcholine mediates its effects through 2 types of acetylcholine receptors (AChRs): nicotinic (nAChR) and muscarinic (mAChR) [Pohanka, 2012]. Four $\mathrm{mAChR}$ subtypes $\left(\mathrm{M}_{1}-\mathrm{M}_{4}\right)$ are identified in the human corpus cavernosum [Traish et al., 1995]. Acetylcholine administration to the equine deep dorsal penile vein induces relaxation in vitro and is mediated by the $\mathrm{mA}$ ChRs (particularly $\mathrm{M}_{3}$ ) [Martínez et al., 2003]. Thus, acetylcholine signalling through $\mathrm{mAChRs}$ can promote tumescence (Fig. 6). This is consistent with the administration of atropine (mAChR antagonist) to the human corpus cavernosum which partially blocks relaxation in response to electrical stimulation in vitro [Saenz de Tejada et al., 1988]. However, as atropine only partially impaired erectile function, acetylcholine-mAChR signalling cannot be the predominant pathway which mediates tumescence [Saenz de Tejada et al., 1988].

Acetylcholine may also drive tumescence via the nAChRs, which are expressed in nerves innervating the rat corpus cavernosum [Faghir-Ghanesefat et al., 2017]. Furthermore, administration of nicotine ( $\alpha 7-\mathrm{nAChR}$ agonist) increases relaxation of the rat corpus cavernosum induced by electric-field stimulation in vitro [FaghirGhanesefat et al., 2017]. Thus, acetylcholine signalling through nAChRs, in addition to mAChRs, may promote tumescence. This is further supported by the blockade of $\mathrm{mAChRs}$ which only attenuates acetylcholine-induced erection in monkeys in vivo, while blockade of both mAChRs and nAChRs abolished it [Stief et al., 1989]. In contrast, nicotine administration can contract (and relax) the rabbit corpus cavernosum in vitro via nAChRs [Nguyen et al., 2015]. Therefore, acetylcholine signalling may also have a role in detumescence.

Nevertheless, cholinergic signalling in the penis is primarily recognised as a driver for tumescence by modulating pro-erectile signalling pathways [Saenz de Tejada et al., 1988]. For example, the administration of NOS inhibitors to the rabbit and rat corpus cavernosum in vitro abolishes acetylcholine-induced relaxation, suggesting acetylcholine drives tumescence by modulating the NOcGMP pathway [Knispel et al., 1991; Faghir-Ghanesefat et al., 2017]. This is consistent with administration of acetylcholine to the rabbit corpus cavernosum in vitro which leads to elevated cGMP levels [Azadzoi et al., 1992].

Acetylcholine-mediated tumescence is endothelium dependent, illustrated by the failure of acetylcholine to relax human corpus cavernosum lacking endothelium in vitro (successful with endothelium) [Saenz de Tejada et al., 1988]. This is consistent with the reduced relaxation response to acetylcholine of the rabbit corpus cavernosum denuded of endothelium [Azadzoi et al., 1992]. Endothelial-dependent acetylcholine signalling is further supported by the presence of $\mathrm{mAchRs}$ in endothelial cells of the human corpus cavernosum (Fig. 6) [Traish et al., 1990].

The effect of acetylcholine on penile endothelium likely involves stimulation of NO. The administration of carbachol (mAchR agonist) augments the erectile response from electrostimulation in wild-type mice, but in contrast it has no effect to that of eNOS-deficient mice [Burnett et al., 2002]. Thus, eNOS mediates the pro-erectile effects of the cholinergic agent carbichol, which likely reflects endothelium-dependent acetylcholine signalling in the penis. Acetylcholine is known to increase intracellular $\mathrm{Ca}^{2+}$ concentration in the endothelium via $\mathrm{mAchRs}$ so that $\mathrm{Ca}^{2+}$ binds to calmodulin to form the Cam-Ca ${ }^{2+}$ complex, in turn activating eNOS, which is a distinct activation pathway compared to eNOS phosphorylation following shear stress described above (Fig. 6) [Zhao et al., 2015; Behringer, 2017]. To the best of our knowledge, this has yet to be proven in the endothelium within the erectile tissue, although it is likely.

These studies show that the interaction of acetylcholine with its receptors mediates tumescence indirectly by promoting the NO-cGMP pathway within the endothelium of the erectile tissue (Fig. 6).

\section{Noradrenaline-Mediated Detumescence}

The sympathetic pathway is responsible for detumescence, and several studies have demonstrated that adrenergic nerves of the sympathetic nervous system innervate the human and rodent erectile tissue [Andersson et al., 2000]. These nerves release the neurotransmitter noradrenaline (NA) which is recognised as the primary agent for detumescence (Fig. 7). Several studies have demonstrated that NA contracts strips of corpus cavernosum, cultured corpus cavernosum cells, and penile artery segments [Andersson and Wagner, 1995]. This is further supported by the presence of a1-adrenoreceptors on smooth muscle cells of the human and rat corpus cavernosum [Costa et al., 1993; Véronneau-Longueville et al., 1998].

Upon release from adrenergic nerve terminals within the erectile tissue, NA binds to $\alpha$-adrenoreceptors 1 and 2 [Traish et al., 2000]. These receptors facilitate smooth muscle contraction and thus detumescence; administra- 
tion of phenylephrine ( $\alpha 1$-adrenoreceptor agonist) and clonidine ( $\alpha 2$-adrenoreceptor agonist) contract the human corpus cavernosum, corpus spongiosum, and cavernous artery in vitro [Hedlund and Andersson, 1985a; Christ et al., 1990]. In addition, administration of agonists for $\alpha$-adrenoreceptors 1 and 2 induce contraction of the rabbit corpus cavernosum in vitro [Gupta et al., 1998].

It is thought that the al-adrenoreceptor is primarily responsible for contraction of the penile smooth muscle; contraction of the human and rabbit corpus cavernosum in organ chambers by electrical field stimulation is attenuated by prazosin, an al-adrenoreceptor antagonist, but not by rauwolscine, an a2-adrenoreceptor antagonist [Saenz de Tejada et al., 1989]. Furthermore, the contractile response of the $\alpha 2$-adrenoreceptor agonist UK 14,304 was approximately half that of phenylephrine in the rabbit corpus cavernosum in vitro [Gupta et al., 1998]. Thus, the $\alpha 1$-adrenoreceptor is the NA receptor primarily responsible for smooth muscle contraction in the corpus cavernosum.

The functional differences between the $\alpha$-adrenoreceptors 1 and 2 may arise from their differential localisation within the erectile tissue. Indeed, both phenylephrine and clonidine contract the human corpus spongiosum and cavernous artery in vitro, although phenylephrine is more potent in corpus spongiosum whereas clonidine is more potent in the cavernous artery [Hedlund and Andersson, 1985a]. Thus, it is likely that $\alpha 1$-adrenoreceptors are the predominant $\alpha$-adrenergic receptors in the corpus spongiosum smooth muscle, whereas a2-adrenoreceptors are predominant in the smooth muscle surrounding the cavernous artery. It is also thought that postsynaptic $\alpha 2$-adrenoreceptors in the penile smooth muscle are positioned more distally from adrenergic nerve terminals in comparison to a 1 adrenoreceptors, potentially explaining the dominant contractile effect of $\alpha 1$-adrenoreceptors [Saenz de Tejada et al., 2000]. However, further studies are needed to confirm this hypothesis. Taken together, these studies show that the $\alpha$-adrenoreceptors are responsible for NA-mediated detumescence.

The mechanism of noradrenergic-induced smooth muscle contraction involves the increase of intracellular $\mathrm{Ca}^{2+}$ concentration (Fig. 7). This is demonstrated by the reduction of NA-induced contraction of the human corpus cavernosum/spongiosum in vitro by either removal of extracellular $\mathrm{Ca}^{2+}$ or administration of $\mathrm{Ca}^{2+}$ channel blockers [Fovaeus et al., 1987]. In addition, smooth muscle cells of the rabbit corpus cavernosum exhibit increased $\mathrm{Ca}^{2+}$ concentration following exposure to NA in vitro while an $\alpha 1$-adrenoreceptor antagonist inhibits the increase of $\mathrm{Ca}^{2+}$ concentration in these cells [Sato and Kawatani, 2002].

Adrenergic signalling via a1-adrenoreceptors raises intracellular $\mathrm{Ca}^{2+}$ levels by activating PLC, which in turn produces $\mathrm{IP}_{3}$ and DAG from $\mathrm{PIP}_{2}$. IP 3 subsequently binds to the $\mathrm{IP}_{3}$-receptors $\left(\mathrm{IP}_{3} \mathrm{Rs}\right)$ which are membrane-bound receptors located in the sarcoplasmic reticulum. They act as $\mathrm{Ca}^{2+}$ channels and upon activation by $\mathrm{IP}_{3}$ release $\mathrm{Ca}^{2+}$ sequestered in the sarcoplasmic reticulum into the cytoplasm [Boittin et al., 1999; Bastin and Heximer, 2011; Narayanan et al., 2012]. In addition, $\mathrm{IP}_{3} \mathrm{R}$-mediated release of $\mathrm{Ca}^{2+}$ activates membrane-bound transient receptor potential canonical 3 (TRPC3) channels which causes an influx of extracellular $\mathrm{Ca}^{2+}$. This results in depolarization which subsequently activates voltage-dependent $\mathrm{Ca}^{2+}$ channels, leading to further $\mathrm{Ca}^{2+}$ influx (Fig. 7) [Narayanan et al., 2012]. It is important to note that these signalling pathways have been identified primarily in vascular tissue outside the erectile tissue of the penis.

Nevertheless, it is likely that activation of these signalling pathways by NA also drives smooth muscle contraction in the penis to cause detumescence. Indeed, administration of NA to the rabbit corpus cavernosum leads to accumulation of inositol phosphates in vitro, including $\mathrm{IP}_{3}$, suggesting the $\alpha$-adrenoreceptors activate PLC [Holmquist et al., 1992]. However, the onset of this reaction is slow as there is a significant increase in inositol phosphate levels only after 15 min of NA exposure, contradicting the rapid contraction of smooth muscle induced by NA [Holmquist et al., 1990, 1992]. This may be due to methodological complexities; further work is required to elucidate the role of $\mathrm{IP}_{3}$ signalling in detumescence [Holmquist et al., 1992].

DAG, the other product of PLC, activates protein kinase $\mathrm{C}$ (PKC) which can also drive smooth muscle contraction [Hilgers and Webb, 2005]. PKC phosphorylates the CPI-17 protein, which in turn inhibits MLCP (drives smooth muscle relaxation) and thus increases $\mathrm{Ca}^{2+}$ sensitization (Fig. 7) [Li et al., 1998; Nunes et al., 2010]. CPI-17 is expressed in the human and rabbit corpus cavernosum, although to the best of our knowledge, smooth muscle contraction in the penis mediated by PKC/CPI-17 signalling has yet to be proven [Jiang and Chitaley, 2012]. However, exposure of the rat corpus cavernosum to phorbol 12-myristate13-acetate (PMA) (PKC activator) potentiates phenylephrine-induced contractions in vitro, while exposure to chelerythine chloride (PKC inhibitor) inhibits it [Husain et al., 2004]. Thus, adrenergic signalling may drive detumescence via activation of PKC. This is 
also supported by the exposure of the rat corpus cavernosum to phenylephrine in vitro which leads to increased levels of PKC isozymes [Husain et al., 2004].

In contrast, studies on the mouse corpus cavernosum show that exposure to chelerythrine (PKC inhibitor) had no significant effects on phenylephrine-induced contractions in vitro, although it significantly reduced phenylephrine-induced contractions in the mouse aorta in vitro [Jin et al., 2008]. This suggests PKC activity does not have a significant role in smooth muscle contraction within the penile vascular bed, in contrast to other areas of the vascular system. Taken together, these data show that PKC may have a role in adrenergic-induced detumescence, although this is not fully resolved, and future studies should address this knowledge gap.

Moreover, Y-27632 (Rho-kinase inhibitor) reduces noradrenergic contractions of human and rabbit corpus cavernosum in vitro in a dose-dependent manner [Rees et al., 2001]. Also, Y-27632 inhibits the contractile effect of methoxamine ( $\alpha 1$-adrenoreceptor agonist) in the rat penis in vivo following autonomic stimulation [Mills et al., 2001a]. Therefore, NA signalling may also activate Rho-kinase (sensitises smooth muscle cells to $\mathrm{Ca}^{2+}$ ) to contract smooth muscle. In summary, NA signalling is a prominent factor driving detumescence via several pathways which increase intracellular $\mathrm{Ca}^{2+}$ concentration and $\mathrm{Ca}^{2+}$ sensitivity within smooth muscle cells (Fig. 7).

\section{Other Signalling Pathways Involved in Detumescence}

Endothelin-1

In addition to NA, several other factors promote detumescence (including some prostanoids described above). Endothelin-1 (ET-1) is considered the most potent contractile agent of smooth muscle within the corpus cavernosum and is produced in human penile smooth muscle cells and endothelial cells in vitro [Saenz de Tejada et al., 1991; Andersson, 2001; Davenport, 2002; Granchi et al., 2002]. In addition, the ET- 1 receptors $\left(\mathrm{ET}_{\mathrm{A}}\right.$ and $\mathrm{ET}_{\mathrm{B}}$ ) have been identified in the corpus cavernosum of humans and other mammals [Carneiro et al., 2008]. Research on isolated cavernosal strips from rats and mice has shown that the association of ET-1 with the $\mathrm{ET}_{\mathrm{A}}$ receptor causes smooth muscle contraction and thus mediates detumescence [Carneiro et al., 2008].

ET-1/ET $\mathrm{A}_{\mathrm{A}}$ signalling mediates smooth muscle contraction by increasing cytosolic $\mathrm{Ca}^{2+}$ concentration, confirmed in smooth muscle cells of the human corpus cavernosum in vitro [Zhao and Christ, 1995]. This is supported by ET- 1 treatment of the rabbit corpus cavernosum which leads to accumulation of inositol phosphates in vi-

Impacts of EDCs on Erectile Dysfunction tro, suggesting that ET-1 also activates PLC in this tissue [Holmquist et al., 1992]. Also, endothelin-induced contractions of the rabbit and human corpus cavernosum are reduced in $\mathrm{Ca}^{2+}$-free solution, or after treatment with nimodipoine $\left(\mathrm{Ca}^{2+}\right.$ channel blocker) [Holmquist et al., 1990]. This demonstrates that ET-1 signalling partly relies on $\mathrm{Ca}^{2+}$ influx to drive smooth muscle contraction. Furthermore, treatment of the rabbit corpus cavernosum with $\mathrm{H}_{7}$ (PKC inhibitor) reduces ET-1-mediated contraction in vitro and abolishes it in $\mathrm{Ca}^{2+}$-free solution [Holmquist et al., 1990]. These results provide evidence that ET-1 drives smooth muscle contraction in the penis by increasing intracellular $\mathrm{Ca}^{2+}$ levels and increasing $\mathrm{Ca}^{2+}$ sensitivity via PKC activation (Fig. 7).

Also, pre-treatment of the Rho-kinase inhibitor Y-27632 prior to intracavernous injection of ET-1 in the rat penis inhibits ET-1-mediated contraction in vivo [Mills et al., 2001a]. Thus, ET-1 may also drive smooth muscle contraction via activation of Rho-kinase (Fig. 7). This is supported by ET-1 administration to the rat corpus cavernosum which leads to dose-dependent contractions in vitro that are relaxed by Y-27632 [Wingard et al., 2003].

Interestingly, combined treatment of ET-1 and phenylephrine ( $\alpha 1$-adrenoreceptor agonist) augmented the contractile response in the rat corpus cavernosum in vitro, compared to ET-1 or phenylephrine treatment alone. Also, the combined ET-1 and phenylephrine treatment correlated with an increase in membrane-RhoA in rat cavernosal tissue homogenates [Wingard et al., 2003]. These studies suggest that ET-1 and NA mediate detumescence in an additive fashion, potentially via increasing activity and levels of RhoA in smooth muscle cells. Also, ET receptor antagonists do not affect smooth muscle contraction of the rabbit corpus cavernosum in vitro induced by the a1-adrenoreceptor, further suggesting that NA and ET-1 mediate detumescence separately to produce an additive effect [Mumtaz et al., 2006]. During tumescence, it is likely that NO signalling inhibits ET-1-mediated vasoconstriction; injection of ET-1 into the rat corpus cavernosum during neural stimulation- or NO donor-induced erection diminishes its ability to contract smooth muscle in vivo [Mills et al., 2001b].

Interestingly, ET-1 signalling via the $\mathrm{ET}_{\mathrm{B}}$ receptor mediates smooth muscle relaxation. This is evident by injection of ET-1 into the rat corpus cavernosum which induces both vasodilation and vasoconstriction [Ari et al., 1996]. Furthermore, administration of an $\mathrm{ET}_{\mathrm{B}}$ agonist leads to relaxation of the rat and mouse corpus cavernosum in vitro [Carneiro et al., 2008]. Also, $\mathrm{ET}_{\mathrm{B}}$ signalling 
increases formation of NO in human fetal endothelial and smooth muscle cells of the penis, potentially explaining the relaxant effect of ET-1/ET $\mathrm{B}$ signalling [Filippi et al., 2003]. These results demonstrate that a single signalling factor can exert opposite effects on erectile function. However, smooth muscle contraction is considered the predominant role of ET-1 in erectile physiology (Fig. 7). This is consistent with administration of ET-1 on the bovine retractor penis muscle and penile artery which induces contraction and not relaxation [Parkkisenniemi and Klinge, 1996].

\section{Angiotensin II}

The peptide hormone angiotensin II is present in the human penile endothelium and smooth muscle cells at physiologically relevant levels (Fig. 7) [Kifor et al., 1997; Ertemi et al., 2011]. Angiotensin II promotes detumescence which is supported by its contraction of the human corpus cavernosum in vitro, an effect blocked by administration of losartan, an antagonist of angiotensin type 1 receptor $\left(\mathrm{AT}_{1}\right)$ [Becker et al., 2001; Ertemi et al., 2011]. Furthermore, intra-cavernosal injection of angiotensin II in canines abolishes spontaneous erections whereas administration of losartan increases intracavernous pressure [Kifor et al., 1997]. Also, transfection of short hairpin RNA to silence the angiotensin II gene using an adenovirus (Ad-Ang-2) in rats with diabetes mellitus-induced erectile dysfunction (DMED) prolonged erectile function in vivo compared to DMED rats without angiotensin II silencing [Zhang et al., 2018]. Also, angiotensin II silencing with this method led to reduced contraction of the corpus cavernosum in vitro of rats with DMED [Zhang et al., 2018].

Angiotensin II promotes detumescence via activation of the RhoA/Rho-kinase pathway (Fig. 7); the expression of RhoA and ROCK2 is lower in the penises of DMED rats exposed to Ad-Ang-2 shRNA compared to DMED controls [Zhang et al., 2018]. Also, similar to NA and ET-1, it is thought that angiotensin II signalling via the $\mathrm{AT}_{1}$ receptor mediates vasoconstriction via activation of PLC, thus generating $\mathrm{IP}_{3}$ and DAG which causes increased $\mathrm{Ca}^{2+}$ and activation of PKC, respectively (Fig. 7) [Wynne et al., 2009]. However, to the best of our knowledge this remains to be proven specifically in the erectile tissue of the penis.

Angiotensin II-induced smooth muscle contraction may also occur via modulation of NA signalling; it was reported that losartan inhibits phenylephrine-induced contraction of the canine corpus cavernosum in vitro [Comiter et al., 1997]. Thus, angiotensin II may interact with NA signalling to promote detumescence. Indeed, angiotensin II can act at sympathetic nerve endings to promote neurotransmission [Reid, 1992]. Therefore, angiotensin II signalling may drive the release of NA from penile sympathetic nerves. Again, to the best of our knowledge this remains to be proven in the penis. Also, administration of the NO donor sodium nitroprusside abolishes angiotensin II-induced contraction of the canine corpus cavernosum in vitro [Comiter et al., 1997]. Thus, NO signalling may also promote tumescence by negatively regulating angiotensin II signalling.

Overall, the balance of relaxant and contractile factors mediated by parasympathetic and sympathetic systems, respectively, determines the contractile state of penile smooth muscle. In addition, multiple other signalling pathways add further complexity to this process.

\section{Link between Endocrine Disrupting Chemicals and Erectile Dysfunction}

\section{Effects of Estrogenic-EDCs and Endogenous Estrogen}

Signalling on Erectile Function

Exposure to EDCs with estrogenic properties (estrogenic-EDCs) during development may impact patterning of erectile tissues in the penis resulting in ED in the adult. Neonatal administration of the estrogenic EDCs diethylstilbestrol (DES) and estradiol valerate (EV) to rat pups during postnatal days 1-12 leads to the accumulation of fat cells in the corpus cavernosum, reduced cavernous spaces, loss of smooth muscle, reduction in weight of the skeletal muscles required for tumescence, and disrupted fertility in adulthood [Goyal et al., 2004a, b, 2005a, b]. A reduction in cavernosal spaces and smooth muscle of the penis is also seen following administration of DES to rats during prepuberty and puberty [Goyal et al., 2004a]. Similarly, treatment of the estrogen 17a-ethinyl estradiol (EE) to neonatal rats results in penile malformations, including the accumulation of fat cells in the penis, reduction of the bulbospongiosus muscle, and impaired fertility in adulthood [Mathews et al., 2009]. This is consistent with BPA administration at toxic levels over 12 days to 8-12 weeks old rabbits (juvenile), which leads to increased thickness of the penile tunica albuginea, subtunical fat deposition, and reduced sinusoidal spaces [Moon et al., 2001]. It is likely that these structural changes to the penis tissues of BPA-exposed rabbits cause the attenuated contraction and relaxation of the corpus cavernosum in vitro that they exhibit in adulthood [Moon et al., 2001]. 
In addition to their developmental impacts, estrogenic-EDC exposure during adulthood may also disrupt erectile function by altering the penile architecture or erectile physiology. Daily treatment of estradiol for 2 weeks in adult rats leads to increased contraction and decreased relaxation of the corpus cavernosum smooth muscle in vitro, as well as disrupted erectile function in vivo [Kataoka et al., 2013]. This is consistent with daily EV administration for 1 and 12 weeks to sexually mature rats which impairs erectile responses in vivo and leads to replacement of corpus cavernosum smooth muscle fibres with loose connective tissue after 12 weeks of EV exposure [Lewis et al., 2002; Adaikan and Srilatha, 2003]. Thus, chronic exposure to EDCs in adults may also lead to smooth muscle atrophy in the penis. In addition, daily administration of EV or the phytoestrogen daidzein over 12 weeks to adult rabbits potentiates contraction of the corpus cavernosum in vitro, as well as decreases the magnitude of relaxation [Srilatha and Adaikan, 2004].

Although estrogenic-EDC exposure during development and adulthood has deleterious effects on erectile function, endogenous estrogen also has a role in penis development which may promote erectile function in the adult. Mice with disrupted endogenous estrogen signalling exhibit accelerated delamination of the penis tissues, impacting the timing of the separation of the prepuce from the glans [Cripps et al., 2019; Govers et al., 2019]. This may in turn disrupt the development of tissues required for erectile function; delamination events are known to cause physical keratin partitions between tissues which block diffusion of patterning and growth factors [Salas et al., 2016; Liu et al., 2017]. Thus, endogenous estrogen signalling during development may be required for the diffusion of growth factors across the developing penis, in turn driving development of the erectile tissue. This is consistent with the potential pro-erectile role of endogenous estrogen during adulthood, which may involve maintaining the structural integrity of erectile tissues, regulating smooth muscle cell ion flux and regulating NO production (described above).

Taken together, it is likely that a balance of endogenous estrogen signalling during development and also in adulthood is required for optimal erectile function. Thus, any EDC which results in an increase or decrease to estrogen signalling may alter this balance to cause ED.

\section{Indirect and Direct Mechanisms for ED Induced by} Estrogenic-EDCs

Estrogenic-EDCs may disrupt penis development and erectile function indirectly via the suppression of testos- terone production; there is evidence that estrogen inhibits the luteinizing hormone ( $\mathrm{LH}$ ) responsiveness of Leydig cells in immature rats, which may in turn decrease circulating testosterone produced in these cells [van Beurden et al., 1978; Schulster et al., 2016]. This is supported by estrogen administration to rabbits and rats which leads to decreased testosterone levels [Adaikan and Srilatha, 2003; Goyal et al., 2004a, 2005a, b; Srilatha and Adaikan, 2004] and by estrogen therapy in male-to-female transsexuals which is associated with a decline in circulating testosterone [Dittrich et al., 2005]. Thus, exogenous estrogen may disrupt erectile function via inhibition of testosterone production, thereby functioning as an anti-androgen.

However, estrogenic-EDCs may also impact erectile function directly as the ERs are expressed throughout the embryonic human and rodent penis [Jesmin et al., 2002; Dietrich et al., 2004; Baskin et al., 2020]. Indeed, testosterone treatment fails to restore erectile function in rats exposed to high levels of estrogen during adulthood, which demonstrates that estrogenic-EDCs may disrupt this process via pathways independent of androgen signalling [Kataoka et al., 2013]. Furthermore, estrogen exposure to the developing tammar wallaby inhibits phallus growth but does not impair normal androgen synthesis, also suggesting a direct action of estrogen in the penis [Chen et al., 2018].

Overall, estrogenic-EDCs may cause ED through inhibition of testosterone production and also by activation of ERs localised in the penis. This may occur during penis development and in adult physiology.

\section{Potential Role of EDCs in Human ED and Other Aspects of Male Reproductive Health}

Although animal studies have made a link between EDCs and ED, it is difficult to investigate this in human populations as the wide range of ED risk factors may confound results [Rambhatla and Mills, 2016]. Nonetheless, there is some evidence that human exposure to EDCs is linked to ED. Factory workers in China exposed to high levels of BPA in the workplace displayed higher risk of male sexual dysfunction, including risk of ED, compared to non-exposed factory workers [Li et al., 2009]. In addition, high BPA levels in urine and blood are an indicator for deteriorating sexual function in men, including erectile function [Li et al., 2010]. Furthermore, EDCs are associated with disruption of several other aspects of male reproductive health. For example, treatment of developing rats with EDCs leads to reduced sperm count [Axelstad et al., 2018], and workplace exposure to BPA in hu- 
mans is associated with decreased sperm count, sperm concentration, sperm vitality, and sperm motility [Li et al., 2011]. Furthermore, developmental abnormalities of the male reproductive system such as hypospadias and cryptorchidism are associated with exposure to EDCs [García et al., 2017], which is supported by animal studies demonstrating that EDC exposure leads to hypospadias [Govers et al., 2019]. Overall, given the complexity of penis development and erectile physiology during adulthood, as well as the multiple ways that both androgens and estrogens impact these processes, it is unsurprising that EDCs can interfere with erectile function. As the pervasiveness of EDCs in our environment correlates with increases in ED prevalence, the potential link between EDCs and ED requires more careful investigation in animals in humans.

\section{Conclusion}

ED is extremely prevalent globally and presents major lifestyle and health problems for affected individuals and their partners. The rapid increase in prevalence cannot be accounted for by genetics and age alone; environmental factors must also play a role. Thus, it is critical to understand this condition and the underlying biology of erectile function. This review summarised the complex interplay between neural, vascular, molecular, and hormonal mechanisms which govern erectile function; disruptions to any of these factors are considered risk factors for ED. However, the role of EDCs as risk factors for ED is starkly under-researched. This is despite established knowledge that androgens and potentially endogenous estrogens are both critical for erectile function in both developmental and adult physiological contexts, EDCs are pervasive in our environment, and multiple animal studies strongly suggest EDCs are among the risk factors for human ED. Thus, this area needs far greater attention in order to reduce ED prevalence and avert the plethora of health hazards presented by EDCs.

\section{Conflict of Interest}

The authors have no conflict of interest to declare.

\section{Funding Sources}

Aspects of this paper were supported by a project grant from the National Health and Medical Research Council to A.J.P.

\section{Author Contributions}

All authors contributed to the writing and editing of the document.

\section{References}

Adaikan PG, Srilatha B. Oestrogen-mediated hormonal imbalance precipitates erectile dysfunction. Int J Impot Res. 2003;15:38-43.

Akkus E, Carrier S, Baba K, Hsu GL, Padma-Nathan $\mathrm{H}$, Nunes L, et al. Structural alterations in the tunica albuginea of the penis: impact of Peyronie's disease, ageing and impotence. $\mathrm{Br}$ J Urol. 1997;79:47-53.

Andersson KE. Pharmacology of penile erection. Pharmacol Rev. 2001;53(3):417-50.

Andersson KE. Mechanisms of penile erection and basis for pharmacological treatment of erectile dysfunction. Pharmacol Rev. 2011; 63(4):811.

Andersson KE, Wagner G. Physiology of penile erection. Physiol Rev. 1995;75:191-236.

Andersson KE, Hedlund P, Alm P. Sympathetic pathways and adrenergic innervation of the penis. Int J Impot Res. 2000;12:S5-S12.

Angulo J, Cuevas P, La Fuente JM, Pomerol JM, Ruiz-Castañé E, Puigvert A, et al. Regulation of human penile smooth muscle tone by prostanoid receptors. Br J Pharmacol. 2002;136: 23-30.
Archer SL. Potassium channels and erectile dysfunction. Vascul Pharmacol. 2002;38:61-71.

Ari G, Vardi Y, Hoffman A, Finberg JPM. Possible role for endothelins in penile erection. Eur J Pharmacol. 1996;307:69-74.

Armagan A, Kim NN, Goldstein I, Traish AM. Dose-response relationship between testosterone and erectile function: evidence for the existence of a critical threshold. J Androl. 2006;27:517-26.

Armagan A, Hatsushi K, Toselli P. The effects of testosterone deficiency on the structural integrity of the penile dorsal nerve in the rat. Int J Impot Res. 2008;20:73-8.

Axelstad M, Hass U, Scholze M, Christiansen S, Kortenkamp A, Boberg J. EDC IMPACT: Reduced sperm counts in rats exposed to human relevant mixtures of endocrine disrupters. Endocr Connect. 2018;7:139-48.

Ayta IA, McKinlay JB, Krane RJ. The likely worldwide increase in erectile dysfunction between 1995 and 2025 and some possible policy consequences. BJU Int. 1999;84:50-6.
Azadzoi KM, Kim N, Brown ML, Goldstein I, Cohen RA, De Tejada IS. Endothelium-derived nitric oxide and cyclooxygenase products modulate corpus cavernosum smooth muscle tone. J Urol. 1992;147:220-5.

Baba K, Yajima M, Carrier S, Akkus E, Reman J, Nunes L, et al. Effect of testosterone on the number of NADPH diaphorase-stained nerve fibers in the rat corpus cavernosum and dorsal nerve. Urology. 2000;56:533-8.

Bachetti T, Comini L, Curello S, Bastianon D, Palmieri M, Bresciani G, et al. Co-expression and modulation of neuronal and endothelial nitric oxide synthase in human endothelial cells. J Mol Cell Cardiol. 2004;37:939-45.

Bacon CG, Mittleman MA, Kawachi I, Giovannucci E, Glasser DB, Rimm EB. A prospective study of risk factors for erectile dysfunction. J Urol. 2006;176:217-21.

Baskin L, Cao M, Sinclair A, Li Y, Overland M, Isaacson D, et al. Androgen and estrogen receptor expression in the developing human penis and clitoris. Differentiation. 2020;111: 41-59. 
Bassiouni W, Daabees T, Louedec L, Norel X, Senbel A. Evaluation of some prostaglandins modulators on rat corpus cavernosum in vitro: Is relaxation negatively affected by COXinhibitors? Biomed Pharmacother. 2019;111: 1458-66.

Bastin G, Heximer SP. Intracellular regulation of heterotrimeric G-protein signaling modulates vascular smooth muscle cell contraction. Arch Biochem Biophys. 2011;510:182-9.

Becker AJ, Uckert S, Stief CG, Truss MC, Machtens S, Scheller F, et al. Possible role of bradykinin and angiotensin II in the regulation of penile erection and detumescence. Urology. 2001;57:193-8.

Behringer EJ. Calcium and electrical signaling in arterial endothelial tubes: New insights into cellular physiology and cardiovascular function. Microcirculation. 2017;24(3):10.1111/ micc. 12328.

Bitsch M, Kromann-Andersen B, Schou J, Sjøntoft $\mathrm{E}$. The elasticity and the tensile strength of tunica albuginea of the corpora cavernosa. J Urol. 1990;143(3):642-5.

Bivalacqua TJ, Rajasekaran M, Champion HC, Wang RUN, Sikka SC, Kadowttz PJ, et al. The Influence of castration on pharmacologically induced penile erection in the cat. J Androl. 1998;19:551-7.

Bivalacqua TJ, Champion HC, Rajasekaran M, Sikka SC, Kadowitz PJ, Doherty PC, et al. Potentiation of erectile response and cAMP accumulation by combination of prostaglandin E1 and rolipram, a selective inhibitor of the type 4 phosphodiesterase (PDE 4). J Urol. 1999;162:1848-55.

Bivalacqua TJ, Diner EK, Novak TE, Vohra Y, Sikka SC, Champion HC, et al. A rat model of Peyronie's disease associated with a decrease in erectile activity and an increase in inducible nitric oxide synthase protein expression. J Urol. 2000;163:1992-8.

Boittin F, Macrez N, Halet G, Mironneau J. Norepinephrine-induced $\mathrm{Ca}(2+)$ waves depend on $\operatorname{Ins} \mathrm{P}(3)$ and ryanodine receptor activation in vascular myocytes. Am J Physiol. 1999;277: C139-51.

Bolton EC, So AY, Chaivorapol C, Haqq CM, Li $\mathrm{H}$, Yamamoto KR. Cell- and gene-specific regulation of primary target genes by the androgen receptor. Genes Dev. 2007;21:200517.

Bosch JLHR, Bénard F, Aboseif S, Stief C, Stackl $\mathrm{W}$, Lue $\mathrm{T}$, et al. Changes in penile hemodynamics after intracavernous injection of prostaglandin E1 and prostaglandin I2 in pigtailed monkeys. Int J Impotence Res. 1989;1

Brann DW, Dhandapani K, Wakade C, Mahesh VB, Khan MM. Neurotrophic and neuroprotective actions of estrogen: basic mechanisms and clinical implications. Steroids. 2007;72: 381-405.

Bredt DS, Snyder SH. Isolation of nitric oxide synthetase, a calmodulin-requiring enzyme. Proc Natl Acad Sci USA. 1990;87:682-5.
Burnett AL, Tillman SL, Chang TS, Epstein JI, Lowenstein CJ, Bredt DS, et al. Immunohistochemical localization of nitric oxide synthase in the autonomic innervation of the human penis. J Urol. 1993;150:73-6.

Burnett AL, Nelson RJ, Calvin DC, Liu J-X, Demas GE, Klein SL, et al. Nitric oxide-dependent penile erection in mice lacking neuronal nitric oxide synthase. Mol Med. 1996;2:28896.

Burnett AL, Chang AG, Crone JK, Huang PL, Sezen SE. Noncholinergic penile erection in mice lacking the gene for endothelial nitric oxide synthase. J Androl. 2002;23:92-7.

Capogrosso P, Colicchia M, Ventimiglia E, Castagna G, Clementi MC, Suardi N, et al. One patient out of four with newly diagnosed erectile dysfunction is a young man--worrisome picture from the everyday clinical practice. J Sex Med. 2013;10:1833-41.

Carneiro FS, Carneiro ZN, Giachini FRC, Lima VV, Nogueira E, Rainey WE, et al. Murine and rat cavernosal responses to endothelin-1 and urotensin-II Vasoactive Peptide Symposium. J Am Soc Hypertens. 2008;2:439-47.

Carrier S, Zvara P, Nunes L, Kour NW, Rehman J, Lue TF. Regeneration of nitric oxide synthase-containing nerves after cavernous nerve neurotomy in the rat. J Urol. 1995;153: $1722-7$.

Cartledge J, Minhas S, Eardley I. The role of nitric oxide in penile erection. Expert Opin Pharmacother. 2001;2:95-107.

Cashen DE, MacIntyre DE, Martin WJ. Effects of sildenafil on erectile activity in mice lacking neuronal or endothelial nitric oxide synthase. Br J Pharmacol. 2002;136:693-700.

Caviedes A, Varas-Godoy M, Lafourcade C, Sandoval S, Bravo-Alegria J, Kaehne T, et al. Endothelial nitric oxide synthase is present in dendritic spines of neurons in primary cultures. Front Cell Neurosci. 2017;11:180.

Ceccatelli S, Grandison L, Scott RE, Pfaff DW, Kow LM. Estradiol regulation of nitric oxide synthase mRNAs in rat hypothalamus. Neuroendocrinology. 1996;64:357-63.

Chen KK, Chan JY, Chang LS, Chen MT, Chan $\mathrm{SH}$. Intracavernous pressure as an experimental index in a rat model for the evaluation of penile erection. J Urol. 1992;147:1124-8.

Chen T, Wu F, Wang X, Ma G, Xuan X, Tang R, et al. Different levels of estradiol are correlated with sexual dysfunction in adult men. Sci Rep. 2020;10:12660.

Chen Y, Yu H, Pask AJ, Fujiyama A, Suzuki Y, Sugano $S$, et al. Hormone-responsive genes in the SHH and WNT/ $\beta$-catenin signaling pathways influence urethral closure and phallus growth. Biol Reprod. 2018;99:806-16.

Chew KK, Stuckey B, Bremner A, Earle C, Jamrozik K. Male erectile dysfunction: its prevalence in Western australia and associated sociodemographic factors. J Sex Med. 2008;5: $60-9$
Chitaley K, Wingard CJ, Clinton Webb R, Branam H, Stopper VS, Lewis RW, et al. Antagonism of Rho-kinase stimulates rat penile erection via a nitric oxide-independent pathway. Nat Med. 2001;7:119-22.

Chiueh CC. Neuroprotective properties of nitric oxide. Ann N Y Acad Sci. 1999;890:301-11.

Christ GJ, Maayani S, Valcic M, Melman A. Pharmacological studies of human erectile tissue: characteristics of spontaneous contractions and alterations in alpha-adrenoceptor responsiveness with age and disease in isolated tissues. Br J Pharmacol. 1990;101:375-81.

Claro J, Aboim J, Andrade E, Alarcon G, Ortiz V, Sampaio F, et al. Histomorphometry of penile smooth muscle fiber in severe erectile dysfunction. Sao Paulo Med J. 2005;123:181-6.

Clement P, Giuliano F. Anatomy and physiology of genital organs - men. In: VodušekBoller DBF, editor. Handbook of Clinical Neurology. Elsevier; 2015. 130. p. 19-37

Colombel M, Droupy S, Paradis V, Lassau JP, Benoît G. Caverno-pudendal nervous communicating branches in the penile hilum. Surg Radiol Anat. 1999;21:273-6.

Comiter CV, Sullivan MP, Yalla SV, Kifor I. Effect of angiotensin II on corpus cavernosum smooth muscle in relation to nitric oxide environment: in vitro studies in canines. Int J Impot Res. 1997;9:135-40.

Cormio L, Gesualdo L, Maiorano E, Bettocchi C, Palumbo F, Traficante A, et al. Vasoactive intestinal polypeptide (VIP) is not an androgendependent neuromediator of penile erection. Int J Impot Res. 2005;17:23-6.

Corona G, Lee DM, Forti G, O'Connor DB, Maggi M, O'Neill TW, et al. Age-related changes in general and sexual health in middle-aged and older men: results from the European Male Ageing Study (EMAS). J Sex Med. 2010; 7:1362-80.

Costa P, Soulie-Vassal ML, Sarrazin B, Rebillard $\mathrm{X}$, Navratil H, Bali JP. Adrenergic receptors on smooth muscle cells isolated from human penile corpus cavernosum. J Urol. 1993;150: 859-63.

Courtois FJ, Charvier KF, Leriche A, Raymond DP. Sexual function in spinal cord injury men. I. Assessing sexual capability. Paraplegia. 1993;31:771-84.

Cripps SM, Mattiske DM, Black JR, Risbridger GP, Govers LC, Phillips TR, et al. A loss of estrogen signaling in the aromatase deficient mouse penis results in mild hypospadias. Differentiation. 2019;109:42-52.

Dashwood MR, Crump A, Shi-Wen X, Loesch A. Identification of neuronal nitric oxide synthase (nNOS) in human penis: a potential role of reduced neuronally-derived nitric oxide in erectile dysfunction. Curr Pharm Biotechnol. 2011;12:1316-21.

Davenport AP. International Union of Pharmacology. XXIX. Update on endothelin receptor nomenclature. Pharmacol Rev. 2002;54:219_ 26. 
de Groat WC. Autonomic Nervous System: Central Urogenital Control. Reference Module in Neuroscience and Biobehavioral Psychology. Amsterdam: Elsevier; 2017.

Diamanti-Kandarakis E, Bourguignon JP, Giudice LC, Hauser R, Prins GS, Soto AM, et al Endocrine-disrupting chemicals: an Endocrine Society scientific statement. Endocr Rev. 2009;30:293-342.

Dietrich W, Haitel A, Huber JC, Reiter WJ. Expression of estrogen receptors in human corpus cavernosum and male urethra. J Histochem Cytochem. 2004;52:355-60.

Dittrich R, Binder H, Cupisti S, Hoffmann I, Beckmann MW, Mueller A. Endocrine treatment of male-to-female transsexuals using gonadotropin-releasing hormone agonist. Exp Clin Endocrinol Diabetes. 2005;113:58692.

Edey AJ, Wilkins CJ, Sidhu PS. Ultrasound of the penis. 3rd ed. In: Allan PL, Baxter GM, Weston MJ, editors. Clinical Ultrasound. Edinburgh: Churchill Livingstone; 2011. p. 62131

Ehmke H, Jünemann KP, Mayer B, Kummer W. Nitric oxide synthase and vasoactive intestinal polypeptide colocalization in neurons innervating the human penile circulation. Int J Impot Res. 1995;7:147-56.

Ertemi H, Mumtaz Faiz H, Howie Alexander J, Mikhailidis Dimitri P, Thompson Cecil S. Effect of angiotensin II and its receptor antagonists on human corpus cavernous contractility and oxidative stress: modulation of nitric oxide mediated relaxation. J Urol. 2011;185: 2414-20.

Escrig ANA, Marin R, Mas M. Repeated PGE1 treatment enhances nitric oxide and erection responses to nerve stimulation in the rat penis by upregulating constitutive NOS isoforms. J Urol. 1999;162:2205-10.

Esposito K, Giugliano F, De Sio M, Carleo D, Di Palo C, D'Armiento M, et al. Dietary factors in erectile dysfunction. Int J Impot Res. 2006; 18:370-4.

Faghir-Ghanesefat H, Rahimi N, Yarmohammadi F, Mokhtari T, Abdollahi AR, Ejtemaei Mehr $\mathrm{S}$, et al. The expression, localization and function of $\alpha 7$ nicotinic acetylcholine receptor in rat corpus cavernosum. J Pharm Pharmacol. 2017;69:1754-61.

Feldman HA, Goldstein I, Hatzichristou DG, Krane RJ, McKinlay JB. Impotence and its medical and psychosocial correlates: results of the Massachusetts Male Aging Study. J Urol. 1994;151:54-61.

Feletou M. The thromboxane/endoperoxide receptor (TP): The common villain. J Cardiovasc Pharmacol. 2010;55:317-32.

Filippi S, Marini M, Vannelli GB, Crescioli C, Granchi S, Vignozzi L, et al. Effects of hypoxia on endothelin-1 sensitivity in the corpus cavernosum. Mol Hum Reprod. 2003;9:76574.
Fisher WA, Rosen RC, Eardley I, Sand M, Goldstein I. Sexual experience of female partners of men with erectile dysfunction: The female experience of men's attitudes to life events and sexuality (FEMALES) study. J Sex Med. 2005;2(5):675-84.

Florian M, Magder S. Estrogen decreases TNFalpha and oxidized LDL induced apoptosis in endothelial cells. Steroids. 2008;73:47-58.

Foresta C, Caretta N, Rossato M, Garolla A, Ferlin A. Role of androgens in erectile function. J Urol. 2004;171:2358-435. quiz 2435.

Fortini F, Vieceli Dalla Sega F, Caliceti C, Aquila G, Pannella M, Pannuti A, et al. Estrogen receptor $\beta$-dependent Notch1 activation protects vascular endothelium against tumor necrosis factor a (TNFa)-induced apoptosis. J Biol Chem. 2017;292:18178-91.

Fovaeus M, Andersson KE, Hedlund H. Effects of some calcium channel blockers on isolated human penile erectile tissues. J Urol. 1987; 138(5):1267-72.

Francis ME, Kusek JW, Nyberg LM, Eggers PW. The contribution of common medical conditions and drug exposures to erectile dysfunction in adult males. J Urol. 2007;178:591-6. discussion 596.

Gandaglia G, Briganti A, Jackson G, Kloner RA, Montorsi F, Montorsi P, et al. A systematic review of the association between erectile dysfunction and cardiovascular disease. Eur Urol. 2014;65:968-78.

García J, Ventura MI, Requena M, Hernández AF, Parrón T, Alarcón R. Association of reproductive disorders and male congenital anomalies with environmental exposure to endocrine active pesticides. Reprod Toxicol. 2017; 71:95-100.

Gavin KM, Seals DR, Silver AE, Moreau KL. Vascular endothelial estrogen receptor alpha is modulated by estrogen status and related to endothelial function and endothelial nitric oxide synthase in healthy women. J Clin Endocrinol Metab. 2009;94:3513-20.

Ghalayini IF. Nitric oxide-cyclic GMP pathway with some emphasis on cavernosal contractility. Int J Impot Res. 2004;16:459-69.

Giuliano F, Rampin O, Allard J. Neurophysiology and pharmacology of female genital sexual response. J Sex Marital Ther. 2002;28 Suppl 1: $101-21$.

Goldstein AMB, Padma-Nathan H. The microarchitecture of the intracavernosal smooth muscle and the cavernosal FIBROUS skeleton. J Urol. 1990;144:1144-6.

Gollapudi L, Oblinger MM. Estrogen and NGF synergistically protect terminally differentiated, ERalpha-transfected PC12 cells from apoptosis. J Neurosci Res. 1999;56:471-81.

Gonzalez-Cadavid NF, Burnett AL, Magee TR, Zeller CB, Vernet D, Smith N, et al. Expression of penile neuronal nitric oxide synthase variants in the rat and mouse penile nerves. Biol Reprod. 2000;63:704-14.
Govers LC, Phillips TR, Mattiske DM, Rashoo N, Black JR, Sinclair A, et al. A critical role for estrogen signaling in penis development. FASEB J. 2019;33:10383-92.

Goyal HO, Braden TD, Williams CS, Dalvi P, Mansour MM, Mansour M, et al. Abnormal morphology of the penis in male rats exposed neonatally to diethylstilbestrol is associated with altered profile of estrogen receptor- $\alpha$ protein, but not of androgen receptor protein: A developmental and immunocytochemical study1. Biol Reprod. 2004a;70:1504-17.

Goyal HO, Braden TD, Williams CS, Dalvi P, Williams JW, Srivastava KK. Exposure of neonatal male rats to estrogen induces abnormal morphology of the penis and loss of fertility. Reprod Toxicol. 2004b; 18:265-74.

Goyal HO, Braden TD, Williams CS, Dalvi P, Mansour M, Williams JW. Estrogen-induced abnormal accumulation of fat cells in the rat penis and associated loss of fertility depends upon estrogen exposure during critical period of penile development. Toxicol Sci. 2005a;87: 242-54.

Goyal HO, Braden TD, Williams CS, Dalvi P, Mansour MM, Williams JW. Permanent induction of morphological abnormalities in the penis and penile skeletal muscles in adult rats treated neonatally with diethylstilbestrol or estradiol valerate: a dose-response study. J Androl. 2005b;26:32-43.

Granchi S, Vannelli GB, Vignozzi L, Crescioli C, Ferruzzi P, Mancina R, et al. Expression and regulation of endothelin-1 and its receptors in human penile smooth muscle cells. Mol Hum Reprod. 2002;8:1053-64.

Grann M, Comerma-Steffensen S, Arcanjo DDR, Simonsen U. Mechanisms involved in thromboxane A2-induced vasoconstriction of rat intracavernous small penile arteries. Basic Clin Pharmacol Toxicol. 2016;119 Suppl 3: 86-95.

Grohe C, Kann S, Fink L, Djoufack PC, Paehr M, van Eickels M, et al. 17 Beta-estradiol regulates nNOS and eNOS activity in the hippocampus. Neuroreport. 2004;15:89-93.

Guidone G, Müller D, Vogt K, Mukhopadhyay AK. Characterization of VIP and PACAP receptors in cultured rat penis corpus cavernosum smooth muscle cells and their interaction with guanylate cyclase-B receptors. Regul Pept. 2002;108:63-72.

Gupta C, Goldman AS. The arachidonic acid cascade is involved in the masculinizing action of testosterone on embryonic external genitalia in mice. Proc Natl Acad Sci USA. 1986;83: 4346-9.

Gupta S, Moreland RB, Yang S, Gallant CM, Goldstein I, Traish A. The expression of functional postsynaptic alpha2-adrenoceptors in the corpus cavernosum smooth muscle. Br J Pharmacol. 1998;123:1237-45.

Han DH, Chae MR, Jung JH, So I, Park JK, Lee SW. Effect of testosterone on potassium channel opening in human corporal smooth muscle cells. J Sex Med. 2008;5:822-32. 
Haynes MP, Li L, Sinha D, Russell KS, Hisamoto $\mathrm{K}$, Baron R, et al. Src kinase mediates phosphatidylinositol 3-kinase/Akt-dependent rapid endothelial nitric-oxide synthase activation by estrogen. J Biol Chem. 2003;278: 2118-23.

Haynes MP, Sinha D, Russell KS, Collinge M, Fulton D, Morales-Ruiz M, et al. Membrane estrogen receptor engagement activates endothelial nitric oxide synthase via the PI3-kinase-Akt pathway in human endothelial cells. Circ Res. 2000;87:677-82.

Heaton JPW, Varrin SJ. Effects of castration and exogenous testosterone supplementation in an animal model of penile erection. J Urol. 1994;151:797-800.

Hedlund H, Andersson KE. Comparison of the responses to drugs acting on adrenoreceptors and muscarinic receptors in human isolated corpus cavernosum and cavernous artery. J Auton Pharmacol. 1985a;5:81-8.

Hedlund H, Andersson KE. Contraction and relaxation induced by some prostanoids in isolated human penile erectile tissue and cavernous artery. J Urol. 1985b;134:1245-50.

Hedlund P, Aszodi A, Pfeifer A, Alm P, Hofmann F, Ahmad M, et al. Erectile dysfunction in cyclic GMP-dependent kinase I-deficient mice. Proc Natl Acad Sci USA. 2000;97:2349-54.

Hilgers RHP, Webb RC. Molecular aspects of arterial smooth muscle contraction: Focus on Rho. Exp Biol Med (Maywood). 2005;230:829-35.

Hill-Eubanks DC, Werner ME, Heppner TJ, Nelson MT. Calcium signaling in smooth muscle. Cold Spring Harb Perspect Biol. 2011;3: a004549-a004549.

Hiremath DS, Geerling EC, Hai L, Narayan P. High levels of androgens cause chondrocyte accumulation and loss of smooth muscle in the mouse penile body. Biol Reprod. 2020; 102:1225-33.

Holmquist F, Andersson KE, Hedlund H. Actions of endothelin on isolated corpus cavernosum from rabbit and man. Acta Physiol Scand. 1990;139:113-22.

Holmquist F, Persson K, Garcia-Pascual A, Andersson KE. Phospholipase $\mathrm{C}$ activation by endothelin-1 and noradrenaline in isolated penile erectile tissue from rabbit. J Urol. 1992; 147:1632-5.

Hsu GL, Brock G, von Heyden B, Nunes L, Lue TF, Tanagho EA. The distribution of elastic fibrous elements within the human penis. $\mathrm{Br}$ J Urol. 1994;73:566-71.

Hsu GL, Hung YP, Tsai MH, Chang HC, Liu SP, Molodysky E, et al. The venous drainage of the corpora cavernosa in the human penis. Arab J Urol. 2013;11:384-91.

Huang PL, Dawson TM, Bredt DS, Snyder SH, Fishman MC. Targeted disruption of the neuronal nitric oxide synthase gene. Cell. 1993; 75:1273-86

Hurt KJ, Musicki B, Palese MA, Crone JK, Becker RE, Moriarity JL, et al. Akt-dependent phosphorylation of endothelial nitric-oxide synthase mediates penile erection. Proc Natl Acad Sci USA. 2002;99:4061-6.
Hurt KJ, Sezen SF, Lagoda GF, Musicki B, Rameau GA, Snyder SH, et al. Cyclic AMP-dependent phosphorylation of neuronal nitric oxide synthase mediates penile erection. Proc Natl Acad Sci USA. 2012;109:16624-9.

Husain S, Young D, Wingard CJ. Role of PKCalpha and PKCiota in phenylephrine-induced contraction of rat corpora cavernosa. Int J Impot Res. 2004;16:325-33.

Iacono F, Barra S, Cafiero G, Lotti T. Scanning electron microscopy of the tunica albuginea of the corpora cavernosa in normal and impotent subjects. Urol Res. 1995;23:221-6.

Jesmin S, Mowa CN, Matsuda N, Salah-Eldin AE, Togashi H, Sakuma I, et al. Evidence for a potential role of estrogen in the penis: detection of estrogen receptor- $\alpha$ and $-\beta$ messenger ribonucleic acid and protein. Endocrinology. 2002; 143:4764-74.

Jiang X, Chitaley K. The promise of inhibition of smooth muscle tone as a treatment for erectile dysfunction: where are we now? Int J Impot Res. 2012;24:49-60.

Jin L, Burnett AL. RhoA/Rho-kinase in erectile tissue: mechanisms of disease and therapeutic insights. Clin Sci (Lond). 2006;110:153-65.

Jin L, Teixeira CE, Webb RC, Leite R. Comparison of the involvement of protein kinase $\mathrm{C}$ in agonist-induced contractions in mouse aorta and corpus cavernosum. Eur J Pharmacol. 2008;590:363-8.

Johannes CB, Araujo AB, Feldman HA, Derby CA, Kleinman KP, McKinlay JB. Incidence of erectile dysfunction in men 40 to 69 years old: longitudinal results from the Massachusetts Male Aging Study. J Urol. 2000;163:460-3.

Johansson HKL, Svingen T. Hedgehog signal disruption, gonadal dysgenesis and reproductive disorders: Is there a link to endocrine disrupting chemicals? Curr Res Toxicol. 2020;1:11623.

Kamm KE, Stull JT. The function of myosin and myosin light chain kinase phosphorylation in smooth muscle. Annu Rev Pharmacol Toxicol. 1985;25:593-620.

Kataoka T, Hotta Y, Ohno M, Maeda Y, Kimura $\mathrm{K}$. Limited effect of testosterone treatment for erectile dysfunction caused by high-estrogen levels in rats. Int J Impot Res. 2013;25:201-5.

Keegan KA, Penson DF. Vasculogenic Erectile Dysfunction. In: Creager M, Beckman J, Loscalzo J, editors. Vascular Medicine: A Companion to Braunwald's Heart Disease. 2nd ed. Philadelphia: W.B. Saunders; 2013. p. 341-8.

Kessler A, Sollie S, Challacombe B, Briggs K, Van Hemelrijck M. The global prevalence of erectile dysfunction: a review. BJU Int. 2019;124: 587-99.

Khan MA, Thompson CS, Sullivan ME, Jeremy JY, Mikhailidis DP, Morgan RJ. The role of prostaglandins in the aetiology and treatment of erectile dysfunction. Prostaglandins Leukot Essent Fatty Acids. 1999;60:169-74.
Kifor I, Williams GH, Vickers MA, Sullivan MP, Jodbert P, Dluhy RG. Tissue angiotensin II as a modulator of erectile function. I. Angiotensin peptide content, secretion and effects in the corpus cavernosum. J Urol. 1997; 157: $1920-5$.

Kim YC, Kim JH, Davies MG, Hagen PO, Carson CC 3rd. Modulation of vasoactive intestinal polypeptide (VIP)-mediated relaxation by nitric oxide and prostanoids in the rabbit corpus cavernosum. J Urol. 1995;153:807-10.

Kirkeby HJ, Andersson KE, Forman A. Comparison of the effects of prostanoids on human penile circumflex veins and corpus cavernosum tissue. Br J Urol. 1993;72:220-5.

Knispel HH, Goessl C, Beckmann R. Basal and acetylcholine-stimulated nitric oxide formation mediates relaxation of rabbit cavernous smooth muscle. J Urol. 1991;146:1429-33.

Krassioukov A, Elliott S. Neural control and physiology of sexual function: Effect of spinal cord injury. Top Spinal Cord Inj Rehabil. 2017;23. $1-10$.

Kuno H, Godschalk M, Mulligan T. Male sexual behavior during aging. In: Hof PR, Mobbs CV, editors. Functional Neurobiology of Aging. San Diego: Academic Press; 2001. p. 739 47.

Lasker GF, Pankey EA, Allain AV, Murthy SN, Stasch JP, Kadowitz PJ. The selective Rho-kinase inhibitor azaindole-1 has long-lasting erectile activity in the rat. Urology. 2013;81: 465-14.e467

Lee SW, Wang HZ, Zhao W, Ney P, Brink PR, Christ GJ. Prostaglandin E1 activates the large-conductance $\mathrm{KCa}$ channel in human corporal smooth muscle cells. Int J Impot Res. 1999;11:189-99.

Lewis EM, Barnett JF Jr. Freshwater L, Hoberman AM, Christian MS. Sexual maturation data for Crl Sprague-Dawley rats: criteria and confounding factors. Drug Chem Toxicol. 2002; 25:437-58

Li D, Zhou Z, Qing D, He Y, Wu T, Miao M, et al. Occupational exposure to bisphenol-A (BPA) and the risk of self-reported male sexual dysfunction. Hum Reprod. 2009;25:519-27.

Li D, Zhou Z, Miao M, He Y, Qing D, Wu T, et al. Relationship between urine bisphenol-A level and declining male sexual function. J Androl. 2010;31:500-6.

Li D, Zhou Z, Miao M, He Y, Wang J, Ferber J, et al. Urine bisphenol-A (BPA) level in relation to semen quality. Fertil Steril. 2011;95:625-4.

Li L, Eto M, Lee MR, Morita F, Yazawa M, Kitazawa T. Possible involvement of the novel CPI17 protein in protein kinase $\mathrm{C}$ signal transduction of rabbit arterial smooth muscle. J Physiol (Lond). 1998;508(Pt 3):871-81.

Lin CS, Chow S, Lau A, Tu R, Lue TF. Regulation of human PDE5A2 intronic promoter by cAMP and cGMP: identification of a critical Sp1-binding site. Biochem Biophys Res Commun. 2001;280:693-9. 
Lin CS, Liu X, Chow S, Lue TF. Cyclic AMP and cyclic GMP activate protein kinase $\mathrm{G}$ in cavernosal smooth muscle cells: old age is a negative factor. BJU Int. 2002;89:576-82.

Lin CS, Lin G, Lue TF.Cyclic nucleotide signaling in cavernous smooth muscle. J Sex Med. 2005; 2:478-91.

Lin CS, Lin G, Xin ZC, Lue TF. Expression, distribution and regulation of phosphodiesterase 5 . Curr Pharm Des. 2006;12:3439-57.

Lin CS, Xin Z, Namiki M, Albersen M, Muller D, Lue TF. Direct androgen regulation of PDE5 gene or the lack thereof. Int J Impot Res. 2013 25:81-5.

Lindner V, Kim S K, Karas R H, Kuiper G G, Gustafsson JÅ, Mendelsohn M E. Increased expression of estrogen receptor-beta mRNA in male blood vessels after vascular injury. Circ Res. 1998;83:224-9.

Linet OI, Neff LL. Intracavernous prostaglandin E1 in erectile dysfunction. Clin Investig. 1994; 72:139-49.

Liu C, Liu ED, Meng YX, Dong XM, Bi YL, Wu $\mathrm{HW}$, et al. Keratin 8 reduces colonic permeability and maintains gut microbiota homeostasis, protecting against colitis and colitisassociated tumorigenesis. Oncotarget. 2017; 8:96774-90.

Liu WJ, Xin ZC, Xin H, Yuan YM, Tian L, Guo YL. Effects of icariin on erectile function and expression of nitric oxide synthase isoforms in castrated rats. Asian J Androl. 2005;7:3818

Lucas KA, Pitari GM, Kazerounian S, Ruiz-Stewart I, Park J, Schulz S, et al. Guanylyl cyclases and signaling by cyclic GMP. Pharmacol Rev. 2000;52:375.

Ludwig W, Phillips M. Organic causes of erectile dysfunction in men under 40. Urol Int. 2014; 92:1-6.

Lue TF. Physiology of penile erection and pathophysiology of erectile dysfunction. In: Wein AJ, Kavoussi LR, Novick AC, Partin AW, Peters CA, editors. Campbell-Walsh Urology. Amsterdam: Elsevier Health Sciences; 2011.

Lugg JA, Rajfer J, González-Cadavid NF. Dihydrotestosterone is the active androgen in the maintenance of nitric oxide-mediated penile erection in the rat. Endocrinology. 1995;136: 1495-501.

Luo H, Yang HF, Jiang R. [Androgen correlates with expressions of ryanodine receptor 1 and voltage-gated calcium channel 1.3 in rat corpus cavernosum smooth muscle]. Zhonghua Nan Ke Xue. 2009;15:895-900.

MacRitchie A N, Jun S S, Chen Z, German Z, Yuhanna IS, Sherman TS, et al. Estrogen upregulates endothelial nitric oxide synthase gene expression in fetal pulmonary artery endothelium. Circ Res. 1997;81:355-62.

Marin R, Escrig A, Abreu P, Mas M. Androgendependent nitric oxide release in rat penis correlates with levels of constitutive nitric oxide synthase isoenzymes. Biol Reprod. 1999; 61:1012-6.
Martin SA, Atlantis E, Lange K, Taylor AW, O'Loughlin P, Wittert GA. Predictors of sexual dysfunction incidence and remission in men. J Sex Med. 2014;11:1136-47.

Martínez AC, Hernández M, Rivera L, Recio P, García-Sacristán A, Benedito S. Muscarinic receptor subtypes mediate vasorelaxation in isolated horse deep dorsal penile vein. Urology. 2003;62:357-61.

Martinez-Piñeiro L, Trigo-Rocha F, Hsu GL, von Heyden B, Lue TF, Tanagho EA. Cyclic guanosine monophosphate mediates penile erection in the rat. Eur Urol. 1993;24:492-9.

Mas M. Molecular mechanisms of penile erection. Arch Esp Urol. 2010;63:589-98.

Massie CE, Adryan B, Barbosa-Morais NL, Lynch AG, Tran MG, Neal DE, et al. New androgen receptor genomic targets show an interaction with the ETS1 transcription factor. EMBO Rep. 2007;8:871-8.

Mathews E, Braden TD, Williams CS, Williams JW, Bolden-Tiller O, Goyal HO. Mal-development of the penis and loss of fertility in male rats treated neonatally with female contraceptive 17alpha-ethinyl estradiol: a doseresponse study and a comparative study with a known estrogenic teratogen diethylstilbestrol. Toxicol Sci. 2009;112:331-43.

McCabe MP, Sharlip ID, Atalla E, Balon R, Fisher $\mathrm{AD}$, Laumann E, et al. Definitions of sexual dysfunctions in women and men: A consensus statement from the Fourth International Consultation on Sexual Medicine 2015. J Sex Med. 2016;13:135-43.

McKinlay JB. The worldwide prevalence and epidemiology of erectile dysfunction. Int J Impot Res. 2000;12(Suppl 4):S6-s11.

McNeill A M, Zhang C, Stanczyk F Z, Duckles S $P$, Krause D N. Estrogen increases endothelial nitric oxide synthase via estrogen receptors in rat cerebral blood vessels: effect preserved after concurrent treatment with medroxyprogesterone acetate or progesterone. Stroke. 2002;33:1685-91.

McVary KT, Carrier S, Wessells H: Smoking and erectile dysfunction: evidence based analysis. J Urol. 2001;166:1624-32.

Mersdorf A, Goldsmith PC, Diederichs W, Padula CA, Lue TF, Fishman IJ, et al. Ultrastructural changes in impotent penile tissue: A comparison of 65 patients. J Urol. 1991;145: 749-58.

Mialon A, Berchtold A, Michaud PA, Gmel G, Suris JC. Sexual dysfunctions among young men: prevalence and associated factors. J Adolesc Health. 2012;51:25-31.

Mills TM, Stopper VS, Wiedmeier VT. Effects of castration and androgen replacement on the hemodynamics of penile erection in the rat. Biol Reprod. 1994;51:234-8.

Mills TM, Chitaley K, Wingard CJ, Lewis RW, Webb RC. Effect of Rho-kinase inhibition on vasoconstriction in the penile circulation. J Appl Physiol. 2001a;91:1269-73.
Mills TM, Pollock D, Lewis R, Branam H, Wingard C. Endothelin-1-induced vasoconstriction is inhibited during erection in rats. Am J Physiol Regul Integr Comp Physiol. 2001b; 281:R476-83

Mills TM, Lewis RW, Wingard CJ, Linder AE, Jin L, Webb RC. Vasoconstriction, RhoA/Rhokinase and the erectile response. Int J Impot Res. 2003;15 Suppl 5:S20-4.

Min J. 17 $\beta$-estradiol-stimulated eNOS gene transcriptional activation is regulated through the estrogen-responsive element in eNOS promoter. Biotechnol Bioprocess Eng. 2007; 12(4):446-9.

Minhas S, Cartledge J, Eardley I. The role of prostaglandins in penile erection. Prostaglandins Leukot Essent Fatty Acids. 2000;62:137-46.

Miyagawa S, Satoh Y, Haraguchi R, Suzuki K, Iguchi T, Taketo MM, et al. Genetic interactions of the androgen and Wnt/beta-catenin pathways for the masculinization of external genitalia. Mol Endocrinol. 2009;23:871-80.

Mizusawa H, Hedlund P, Hakansson A, Alm P, Andersson KE. Morphological and functional in vitro and in vivo characterization of the mouse corpus cavernosum. Br J Pharmacol. 2001;132:1333-41.

Moon DG, Sung DJ, Kim YS, Cheon J, Kim JJ. Bisphenol A inhibits penile erection via alteration of histology in the rabbit. Int J Impot Res. 2001;13:309-16.

Morelli A, Filippi S, Mancina R, Luconi M, Vignozzi L, Marini M, et al. Androgens regulate phosphodiesterase type 5 expression and functional activity in corpora cavernosa. Endocrinology. 2004;145:2253-63.

Müller SC, Hsieh JT, Lue TF, Tanagho EA. Castration and erection. An animal study. Eur Urol. 1988;15:118-24.

Mumtaz FH, Lau DH, Siddiqui EJ, Thompson CS, Morgan RJ, Mikhailidis DP. Pharmacological properties of endothelin-1 in the rabbit corpus cavernosum. In Vivo. 2006;20:243-6.

Murakami R. A histological study of the development of the penis of wild-type and androgeninsensitive mice. J Anat. 1987;153:223-31.

Musicki B, Champion HC, Becker RE, Liu T, Kramer MF, Burnett AL. Erection capability is potentiated by long-term sildenafil treatment: role of blood flow-induced endothelial nitric-oxide synthase phosphorylation. Mol Pharmacol. 2005;68:226-32.

Narayanan D, Adebiyi A, Jaggar JH. Inositol trisphosphate receptors in smooth muscle cells. Am J Physiol Heart Circ Physiol. 2012;302: H2190-210.

Nehra A, Azadzoi KM, Moreland RB, Pabby A, Siroky MB, Krane RJ, et al. Cavernosal expandability is an erectile tissue mechanical property which predicts trabecular histology in an animal model of vasculogenic erectile dysfunction. J Urol. 1998;159:2229-36.

Nguyen HB, Lee SY, Park SH, Han JH, Lee MY, Myung SC. Nicotine in high concentration causes contraction of isolated strips of rabbit corpus cavernosum. Korean J Physiol Pharmacol. 2015;19:257-62. 
Nilsen J, Chen S, Irwin RW, Iwamoto S, Brinton $\mathrm{RD}$. Estrogen protects neuronal cells from amyloid beta-induced apoptosis via regulation of mitochondrial proteins and function. BMC Neurosci. 2006;7:74.

Nordin RB, Soni T, Kaur A, Loh KP, Miranda S. Prevalence and predictors of erectile dysfunction in adult male outpatient clinic attendees in Johor, Malaysia. Singapore Med J. 2019;60: 40-7.

Nunes KP, Rigsby CS, Webb RC. RhoA/Rho-kinase and vascular diseases: what is the link? Cell Mol Life Sci. 2010;67:3823-36.

Ottesen B, Wagner G, Virag R, Fahrenkrug J. Penile erection: possible role for vasoactive intestinal polypeptide as a neurotransmitter. $\mathrm{Br}$ Med J (Clin Res Ed). 1984;288:9-11.

Palese MA, Crone JK, Burnett AL. A castrated mouse model of erectile dysfunction. J Androl. 2003;24:699-703.

Palmer LS, Valcic M, Melman A, Giraldi A, Wagner G, Christ GJ. Characterization of cyclic AMP accumulation in cultured human corpus cavernosum smooth muscle cells. J Urol. 1994; 152:1308-14.

Panchatsharam PK, Durland J, Zito PM. Physiology, Erection. StatPearls. Treasure Island: StatPearls Publishing; 2020.

Park KH, Kim SW, Kim KD, Paick JS. Effects of androgens on the expression of nitric oxide synthase mRNAs in rat corpus cavernosum. BJU Int. 1999;83:327-33.

Parkkisenniemi UM, Klinge E. Functional characterization of endothelin receptors in the bovine retractor penis muscle and penile artery. Pharmacol Toxicol. 1996;79:73-9.

Penson DF, Ng C, Cai L, Rajfer J, González-Cadavid NF. Androgen and pituitary control of penile nitric oxide synthase and erectile function in the rat. Biol Reprod. 1996;55:567-74.

Pickard RS, Powell PH, Zar MA. Evidence against vasoactive intestinal polypeptide as the relaxant neurotransmitter in human cavernosal smooth muscle. Br J Pharmacol. 1993;108: 497-500.

Pohanka M. Alpha7 nicotinic acetylcholine receptor is a target in pharmacology and toxicology. Int J Mol Sci. 2012;13:2219-38.

Polak JM, Mina S, Gu J, Bloom SR. Vipergic nerves in the penis. Lancet. 1981;2:217-9.

Puglisi R, Mattia G, Carè A, Marano G, Malorni W, Matarrese P. Non-genomic effects of estrogen on cell homeostasis and remodeling with special focus on cardiac ischemia/reperfusion injury. Front Endocrinol (Lausanne). 2019; 10:733.

Quartey JKM. Anatomy and blood supply of the urethra and penis. In: Schreiter F, Jordan G, editors. Urehtral Reconstructive Surgery. Berlin: Springer; 2006. p. 11-7.

Rainville J, Pollard K, Vasudevan N. Membraneinitiated non-genomic signaling by estrogens in the hypothalamus: cross-talk with glucocorticoids with implications for behavior. Front Endocrinol (Lausanne). 2015;6:18-.
Rambhatla A, Mills JN. Impact of the environment on male sexual health. Curr Sex Health Rep. 2016;8(1):1.

Ramírez R, Pedro-Botet J, García M, Corbella E, Merino J, Zambón D, et al. Erectile dysfunction and cardiovascular risk factors in a Mediterranean diet cohort. Intern Med J. 2016;46: 52-6.

Rastrelli G, Maggi M. Erectile dysfunction in fit and healthy young men: psychological or pathological? Transl Androl Urol. 2017;6:7990.

Rees RW, Ralph DJ, Royle M, Moncada S, Cellek S. Y-27632, an inhibitor of Rho-kinase, antagonizes noradrenergic contractions in the rabbit and human penile corpus cavernosum. $\mathrm{Br}$ J Pharmacol. 2001;133:455-8.

Reeves F, Everaerts W, Murphy DG, Costello A. The surgical anatomy of the prostate. In: Mydlo JH, Godec CJ, editors. Prostate Cancer. 2nd ed. San Diego: Academic Press; 2016. p. 253-63.

Reid IA. Interactions between ANG II, sympathetic nervous system, and baroreceptor reflexes in regulation of blood pressure. Am J Physiol. 1992;262:E763-78.

Reilly CM, Zamorano P, Stopper VS, Mills TM. Androgenic regulation of NO availability in rat penile erection. J Androl. 1997;18:110-5.

Rembold CM. Regulation of contraction and relaxation in arterial smooth muscle. Hypertension. 1992;20:129-37.

Rhoden EL, Telöken C, Sogari PR, Vargas Souto CA. The use of the simplified International Index of Erectile Function (IIEF-5) as a diagnostic tool to study the prevalence of erectile dysfunction. Int J Impot Res. 2002;14:245-50.

Ricciotti E, FitzGerald GA. Prostaglandins and inflammation. Arterioscler Thromb Vasc Biol. 2011;31(5):986-1000.

Rubanyi GM, Freay AD, Kauser K, Sukovich D, Burton G, Lubahn DB, et al. Vascular estrogen receptors and endothelium-derived nitric oxide production in the mouse aorta. Gender difference and effect of estrogen receptor gene disruption. J Clin Invest. 1997;99:2429-37.

Ruiz Rubio JL, Hernandez M, Rivera de los Arcos L, Martinez AC, Garcia-Sacristan A, Prieto D. Mechanisms of prostaglandin E1-induced relaxation in penile resistance arteries. J Urol. 2004;171:968-73.

Saenz de Tejada I. Molecular mechanisms for the regulation of penile smooth muscle contractility. Int J Impot Res. 2002;14(Suppl 1):S610.

Saenz de Tejada I, Blanco R, Goldstein I, Azadzoi K, de las Morenas A, Krane RJ, et al. Cholinergic neurotransmission in human corpus cavernosum. I. Responses of isolated tissue. Am J Physiol. 1988;254:H459-67.

Saenz de Tejada I, Kim NN, Lagan I, Krane RJ. Goldstein I. Regulation of adrenergic activity in penile corpus cavernosum. J Urol. 1989; $142: 1117-21$
Saenz de Tejada I, Carson MP, de las Morenas A, Goldstein I, Traish AM. Endothelin: localization, synthesis, activity, and receptor types in human penile corpus cavernosum. Am J Physiol. 1991;261:H1078-1085.

Saenz de Tejada I, Kim NN, Goldstein I, Traish AM. Regulation of pre-synaptic alpha adrenergic activity in the corpus cavernosum. Int J Impot Res. 2000;12(Suppl 1):S20-25.

Salas PJ, Forteza R, Mashukova A. Multiple roles for keratin intermediate filaments in the regulation of epithelial barrier function and apicobasal polarity. Tissue Barriers. 2016;4: e1178368.

Sassone-Corsi P. The cyclic AMP pathway. Cold Spring Harb Perspect Biol. 2012;4(12): a011148.

Sathyanarayana Rao TS, Darshan MS, Tandon A. An epidemiological study of sexual disorders in south Indian rural population. Indian J Psychiatry. 2015;57:150-7.

Sato M, Kawatani M. Effects of noradrenaline on cytosolic concentrations of $\mathrm{Ca}(2+)$ in cultured corpus cavernosum smooth muscle cells of the rabbit. Neurosci Lett. 2002;324: 89-92.

Sauzeau V, Le Jeune H, Cario-Toumaniantz C, Smolenski A, Lohmann SM, Bertoglio J, et al. Cyclic GMP-dependent protein kinase signaling pathway inhibits RhoA-induced $\mathrm{Ca} 2+$ sensitization of contraction in vascular smooth muscle. J Biol Chem. 2000;275: 21722-9.

Sazova O, Kadioğlu A, Gürkan L, Kayaarasi Z, Bross $\mathrm{S}$, Manning $\mathrm{M}$, et al. Intracavernous administration of SIN-1+VIP in an in vivo rabbit model for erectile function. Int J Impot Res. 2002;14:44-9.

Schirar A, Bonnefond C, Meusnier C, Devinoy E. Androgens modulate nitric oxide synthase messenger ribonucleic acid expression in neurons of the major pelvic ganglion in the rat. Endocrinology. 1997;138:3093-102.

Schulster M, Bernie A, Ramasamy R. The role of estradiol in male reproductive function. Asian J Androl. 2016;18:435-40.

Seftel AD, Vaziri ND, Ni Z, Razmjouei K, Fogarty J, Hampel N, et al. Advanced glycation end products in human penis: elevation in diabetic tissue, site of deposition, and possible effect through iNOS or eNOS. Urology. 1997;50: 1016-26.

Seo SI, Kim SW, Paick JS. The effects of androgen on penile reflex, erectile response to electrical stimulation and penile NOS activity in the rat. Asian J Androl. 1999;1:169-74.

Shabsigh R. The effects of testosterone on the cavernous tissue and erectile function. World J Urol. 1997;15:21-6.

Shen Z, Chen Z, Lu Y, Chen F, Chen Z. Relationship between gene expression of nitric oxide synthase and androgens in rat corpus cavernosum. Chin Med J. 2000a;113:1092-5.

Shen ZJ, Lu YL, Chen ZD, Chen F, Chen Z. Effects of androgen and ageing on gene expression of vasoactive intestinal polypeptide in rat corpus cavernosum. BJU Int. 2000b;86:133-7. 
Shen ZJ, Zhou XL, Lu YL, Chen ZD. Effect of androgen deprivation on penile ultrastructure. Asian J Androl. 2003;5:33-6.

Singh R, Artaza JN, Taylor WE, Gonzalez-Cadavid NF, Bhasin S. Androgens stimulate myogenic differentiation and inhibit adipogenesis in $\mathrm{C} 3 \mathrm{H} 10 \mathrm{~T} 1 / 2$ pluripotent cells through an androgen receptor-mediated pathway. Endocrinology. 2003;144:5081-8.

Smith AL, Axilrod AC. Male sexual dysfunction. In: Hanno PM, Malkowicz SB, Wein AJ, editors. Penn Clinical Manual of Urology. Philadelphia: W.B. Saunders; 2007. p. 665-706

Spyridopoulos I, Sullivan AB, Kearney M, Isner JM, Losordo DW. Estrogen-receptor-mediated inhibition of human endothelial cell apoptosis. Estradiol as a survival factor. Circulation. 1997;95:1505-14.

Srilatha B, Adaikan PG. Estrogen and phytoestrogen predispose to erectile dysfunction: do ER- $\alpha$ and ER- $\beta$ in the cavernosum play a role? Urology. 2004;63:382-6.

Stief C, Benard F, Bosch R, Aboseif S, Nunes L, Lue TF, et al. Acetylcholine as a possible neurotransmitter in penile erection. J Urol. 1989; 141:1444-8.

Suh JK, Mun KH, Cho CK, Shin HC, Kim YS, Park TC. Effect of vasoactive intestinal peptide and acetylcholine on penile erection in the rat in vivo. Int J Impot Res. 1995;7:111-8.

Suzuki N, Sato Y, Hisasue S, Kato R, Suzuki K, Tsukamoto T. Effect of testosterone on intracavernous pressure elicited with electrical stimulation of the medial preoptic area and cavernous nerve in male rats. J Androl. 2007; 28:218-22.

Takahashi Y, Hirata Y, Yokoyama S, Ishii N, Nunes L, Lue TF, et al. Loss of penile erectile response to intracavernous injection of acetylcholine in castrated dog. Tohoku J Exp Med. 1991;163:85-91.

Tomada I, Tomada N, Almeida H, Neves D. Androgen depletion in humans leads to cavernous tissue reorganization and upregulation of Sirt1-eNOS axis. Age (Dordr). 2013;35:3547.

Traish AM. Androgens play a pivotal role in maintaining penile tissue architecture and erection: a review. J Androl. 2009;30:363-9.

Traish AM, Carson MP, Kim NN, Goldstein I, Saenz De Tejada I. Characterization of muscarinic acetylcholine receptors in human penile corpus cavernosum: Studies on whole tissue and cultured endothelium. J Urol. 1990; 144:1036-40.

Traish AM, Palmer MS, Goldstein I, Moreland $\mathrm{RB}$. Expression of functional muscarinic acetylcholine receptor subtypes in human corpus cavernosum and in cultured smooth muscle cells. Receptor. 1995;5:159-76.

Traish AM, Park K, Dhir V, Kim NN, Moreland $\mathrm{RB}$, Goldstein I. Effects of castration and androgen replacement on erectile function in a rabbit model. Endocrinology. 1999; 140: 1861-8.
Traish AM, Kim NN, Moreland RB, Goldstein I. Role of alpha adrenergic receptors in erectile function. Int J Impot Res. 2000;12(Suppl 1): S48-63.

Traish AM, Munarriz R, O'Connell L, Choi S, Kim SW, Kim NN, et al. Effects of medical or surgical castration on erectile function in an animal model. J Androl. 2003;24:381-7.

Tsametis CP, Isidori AM. Testosterone replacement therapy: for whom, when and how? Metabolism. 2018;86:69.

Turko IV, Ballard SA, Francis SH, Corbin JD. Inhibition of cyclic GMP-binding cyclic GMPspecific phosphodiesterase (Type 5) by sildenafil and related compounds. Mol Pharmacol. 1999;56:124.

Udelson D, L'Esperance J, Morales A, Patel R, Goldstein I. The mechanics of corporal venoocclusion in penile erection: A theory on the effect of stretch-associated luminal constrictability on outflow resistance. Int J Impot Res. 2001;12:315-27.

Urciuoli R, Cantisani TA, Carlini M, Giuglietti M, Botti FM. Prostaglandin E1 for treatment of erectile dysfunction. Cochrane Database of Systematic Reviews. 2004.

van Beurden WM, Roodnat B, Mulder E, van der Molen HJ. Further characterization of the effects of hypophysectomy, FSH and estrogen on LH stimulation of testosterone production in Leydig cells isolated from immature rats. Steroids. 1978;31:83-98.

Véronneau-Longueville $\mathrm{F}$, Rampin $\mathrm{O}$, Jardin A, Benoit G, Giuliano F. Expression of alpha 1 adrenoceptor subtypes in rat corpus cavernosum. Int J Impot Res. 1998;10:187-94.

Virag R, Zwang G, Dermange H, Legman M. Vasculogenic impotence: A review of 92 cases with 54 surgical operations. Vascular Surgery. 1981;15(1):9-17.

Waldkirch E, Ückert S, Schultheiss D, Geismar U, Bruns C, Scheller F, et al. Non-genomic effects of androgens on isolated human vascular and nonvascular penile erectile tissue. BJU Int. 2008;101:71-5.

Wang H, Eto M, Steers WD, Somlyo AP, Somlyo $\mathrm{AV}$. RhoA-mediated $\mathrm{Ca} 2+$ sensitization in erectile function. J Biol Chem. 2002;277: 30614-21.

Weber MF, Smith DP, O'Connell DL, Patel MI, de Souza PL, Sitas F, et al. Risk factors for erectile dysfunction in a cohort of 108477 Australian men. Med J Aust. 2013;199:107-11.

Wen J, Grenz A, Zhang Y, Dai Y, Kellems RE, Blackburn MR, et al. A2B adenosine receptor contributes to penile erection via PI3K/AKT signaling cascade-mediated eNOS activation. Faseb J. 2011;25:2823-30.

Wen Y, Perez EJ, Green PS, Sarkar SN, Simpkins JW. nNOS is involved in estrogen mediated neuroprotection in neuroblastoma cells. Neuroreport. 2004;15:1515-8.

Willis EA, Ottesen B, Wagner G, Sundler F, Fahrenkrug J. Vasoactive intestinal polypeptide (vip) as a putative neurotransmitter in penile erection. Life Sci. 1983;33:383-91.
Wingard CJ, Husain S, Williams J, James S. RhoA-Rho kinase mediates synergistic ET-1 and phenylephrine contraction of rat corpus cavernosum. Am J Physiol Regul Integr Comp Physiol. 2003;285:R1145-52.

Wynne BM, Chiao C-W, Webb RC. Vascular smooth muscle cell signaling mechanisms for contraction to angiotensin II and endothelin-1. J Am Soc Hypertens. 2009;3:84-95.

Xia Y, Krukoff TL. Estrogen induces nitric oxide production via activation of constitutive nitric oxide synthases in human neuroblastoma cells. Endocrinology. 2004;145:4550-7.

Yafi FA, Jenkins L, Albersen M, Corona G, Isidori AM, Goldfarb S, et al. Erectile dysfunction. Nat Rev Dis Primers. 2016;2:16003-.

Yang R, Huang YC, Lin G, Wang G, Hung S, Dai YT, et al. Lack of direct androgen regulation of PDE5 expression. Biochem Biophys Res Commun. 2009;380:758-62.

Yang S, Bae L, Zhang L. Estrogen increases eNOS and NOx release in human coronary artery endothelium. J Cardiovasc Pharmacol. 2000; 36:242.

Yang Y, Song Y, Lu Y, Xu Y, Liu L, Liu X. Associations between erectile dysfunction and psychological disorders (depression and anxiety): A cross-sectional study in a Chinese population. Andrologia. 2019;51:e13395.

Yilmaz U, Ellis W, Lange P, Yang C. Evoked cavernous activity: measuring penile autonomic innervation following pelvic surgery. Int J Impot Res. 2006;18:296-301.

Zhang L, Li X, Zhao L, Zhang L, Zhang G, Wang $J$, et al. Nongenomic effect of estrogen on the MAPK signaling pathway and calcium influx in endometrial carcinoma cells. J Cell Biochem. 2009; 106:553-62.

Zhang MG, Shen ZJ, Zhang CM, Wu W, Gao PJ, Chen SW, et al. Vasoactive intestinal polypeptide, an erectile neurotransmitter, improves erectile function more significantly in castrated rats than in normal rats. BJU Int. 2011;108: 440-6.

Zhang X, Morelli A, Luconi M, Vignozzi L, Filippi S, Marini M, et al. Testosterone regulates PDE5 expression and in vivo responsiveness to tadalafil in rat corpus cavernosum. Eur Urol. 2005;47:409-16.

Zhang Y, Jia L, Zhang Y, Ji W, Li H. Angiotensin II silencing alleviates erectile dysfunction through down-regulating the Rhoa/Rho kinase signaling pathway in rats with diabetes mellitus. Cell Physiol Biochem. 2018;45:41927.

Zhao W, Christ GJ. Endothelin-1 as a putative modulator of erectile dysfunction. II. Calcium mobilization in cultured human corporal smooth muscle cells. J Urol. 1995;154:1571-9.

Zhao Y, Vanhoutte PM, Leung SW. Vascular nitric oxide: Beyond eNOS. J Pharmacol Sci. 2015;129:83-94.

Zvara P, Sioufi R, Schipper HM, Begin LR, Brock GB. Nitric oxide mediated erectile activity is a testosterone dependent event: a rat erection model. Int J Impot Res. 1995;7:209-19. 